\title{
On the structure of the extra-tropical transition layer from in-situ observations
}

I. Pisso ${ }^{1,3}$, K. S. Law ${ }^{1}$, F. Fierli ${ }^{2}$, P. H. Haynes ${ }^{3}$, P. Hoor ${ }^{4}$, E. Palazzi ${ }^{5}$, F. Ravegnani ${ }^{2}$, and S. Viciani ${ }^{6}$

${ }^{1}$ UPMC Univ. Paris 06, Université Versailles St-Quentin, CNRS/INSU, UMR8190, LATMOS-IPSL, Paris, France

${ }^{2}$ ISAC-CNR, Bologna, Italy

${ }^{3}$ DAMTP, University of Cambridge, UK

${ }^{4}$ University of Mainz, Germany

${ }^{5}$ ISAC-CNR, Torino, Italy

${ }^{6}$ INO-CNR, Firenze, Italy

Received: 16 August 2012 - Accepted: 8 October 2012 - Published: 25 October 2012

Correspondence to: I. Pisso (ignacio.pisso@latmos.ipsl.fr)

Published by Copernicus Publications on behalf of the European Geosciences Union.

\section{Extra tropical} transition layer

I. Pisso et al.
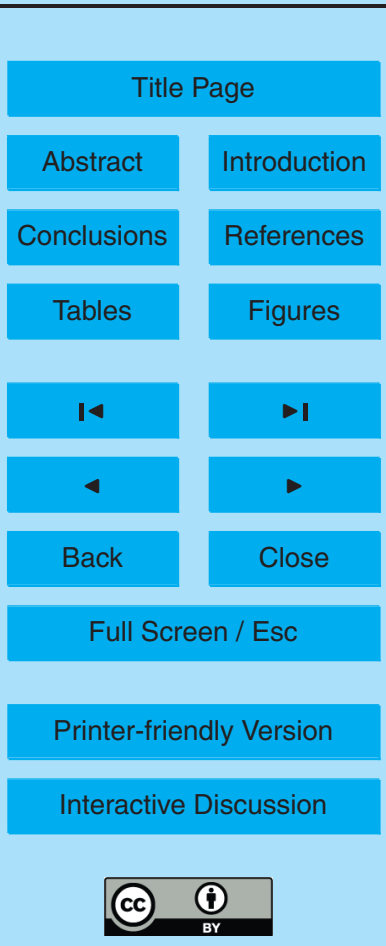


\section{Abstract}

In-situ observations of atmospheric tracers from multiple measurement campaigns over the period 1994-2007 were combined to investigate the Extra-tropical Transition Layer (ExTL) region and the properties of large scale meridional transport. We used potential

5 temperature, equivalent latitude and distance relative to the local dynamical tropopause as vertical coordinates to highlight the behaviour of trace gases in the tropopause region. Vertical coordinates based on constant PV surfaces allowed us to relate the dynamical definition of the tropopause with trace gases distributions and vertical gradients and hence analyse its latitudinal dependence and seasonal variability. Analysis of the available data provides a working definition of the upper limit of the ExTL based on the upper limit of the region of high vertical $\mathrm{CO}$ gradient in PV relative coordinates. A secondary local maximum in vertical $\mathrm{O}_{3}$ gradient can be used a proxy for the lower limit, although it is less clearly defined than that of $\mathrm{CO}$. The sloping isopleths of $\mathrm{CO}$ and $\mathrm{O}_{3}$ mixing ratios and the $\mathrm{CO}$ mixing ratio gradient are consistent with isopleths in purely dynamical diagnostics such as $\chi_{30}$, the proportion of air masses in contact with the PBL within one month and underline the differences between the PV based and chemical tropopauses. The use of tropopause relative coordinates allows different seasons to be analysed together to produce climatological means. The weak dependence of dynamical diagnostics of transport on the absolute values of tracer concentrations makes them a suitable process-oriented tool to evaluate global chemical models and make Lagrangian comparisons.

\section{Introduction}

Physical and chemical processes governing transport and transformation of air masses across the upper troposphere - lower stratosphere region (UTLS) determine the impact of surface emissions on the chemical composition of the stratosphere and on its radiative properties (WMO, 2007). Chemical species emitted from the surface, transformed

\section{Extra tropical transition layer}

I. Pisso et al.

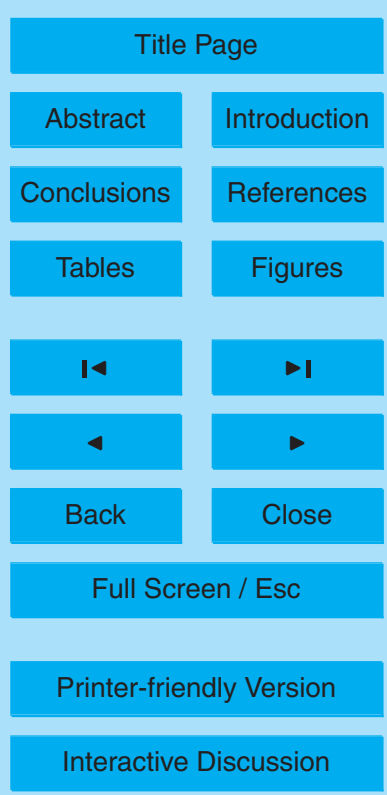


along their passage across the troposphere and injected into the stratosphere include very short lived halogenated species, with potentially significant impact on stratospheric $\mathrm{O}_{3}$ (ozone) and pollutants affecting the atmospheric radiative balance. Conversely, subsidence of stratospheric air masses brings large amounts of stratospheric $5 \mathrm{O}_{3}$ into the troposphere (Bethan et al., 1996). Estimates of the net flux are on the order of $400 \pm 100 \mathrm{Tgyr}^{-1}$ (Stevenson et al., 2006). Uncertainties in this flux have significant implications for background ozone concentrations in the troposphere and an accurate characterisation of the transition region is desirable in choosing control surfaces that minimise such uncertainties (Collins et al., 2003). The tropopause, the notional bound10 ary between the troposphere and the stratosphere, is not an impermeable surface and a permanent two way exchange upward (Troposphere-to-Stratosphere Transport, TST) and downward (Stratosphere-to-Troposphere Transport, STT) occurs (Holton et al., 1995). The tropopause region, in addition to its importance for $\mathrm{O}_{3}$ budgets and trends and its link to tropospheric chemistry and air quality, also has strong implications for 15 the radiative balance of the troposphere and climate change prediction. It is therefore critical to understand interconnections between dynamics and chemistry in the UTLS.

Between the troposphere and the stratosphere, both in the tropics and in midlatitudes, a transition region establishes with mixed tropospheric and stratospheric characteristics in terms of chemical composition (Hoor et al., 2004). Air masses en20 ter into the stratosphere predominantly in the tropics, equatorward from the jet streams and the bulk of convective outflow occurs near $200 \mathrm{hPa}$ over the inter-tropical convergence zone (ITCZ), at the base of the tropical transition layer (TTL) as summarised by Fueglistaler et al. (2009). Nevertheless, mid latitude convection and frontal uplift can inject tropospheric air directly into the stratosphere in the mid latitudes. The result is a layer within the UTLS above the mid latitude tropopause where the air has intermediate signatures between tropospheric and stratospheric air. The extratropical transition layer is a key region involved in transport and chemistry processes mentioned above and several questions remain related to how and where air is transported across it, the time scales involved, and how air is chemically transformed during its passage.
ACPD

12, 28033-28068, 2012

\section{Extra tropical transition layer}

I. Pisso et al.

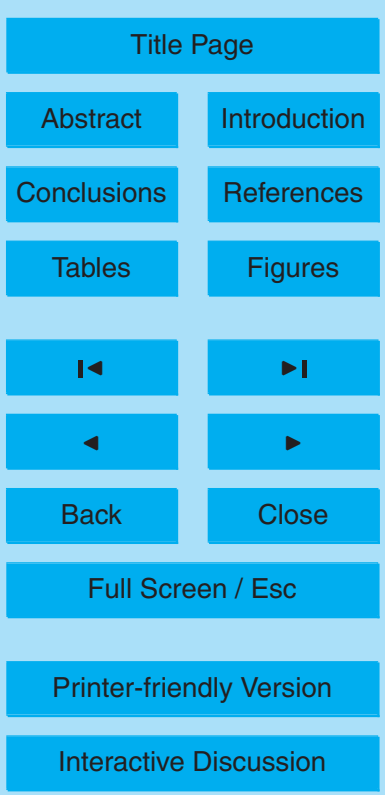


Analysis of in-situ observations permit examination of the small scale structures in composition and gradients of chemical tracers within this extra-tropical transition layer. Pan et al. (2004), based on the STRAT and POLARIS airborne campaigns characterised the structure of the ExTL from tracer correlations, concluding that in the extra 5 tropics (at $40^{\circ} \mathrm{N}$ and $65^{\circ} \mathrm{N}$ ) the chemical transition occurs in the vicinity of the thermal tropopause and raising several issues about the use of PV to define the tropopause. Hoor et al. (2004) estimated the seasonality and thickness of the ExTL over Europe from SPURT CO observations deriving a depth of $30 \mathrm{~K}$ above the $2 \mathrm{PVU}$ surface in summer and $20-25 \mathrm{~K}$ in winter. Previous studies (Pan et al., 2004; Hegglin et al., 10 2009) aimed to define the ExTL in terms of statistical descriptions of the dispersion with respect to a mean value based on measurements of typical mixing ratios in the troposphere and stratosphere and tracer-tracer correlations. Despite recent advances, several outstanding questions remain concerning the balance of processes that govern the chemical composition of the ExTL including how they vary in space and time, what

different tracers tell us about the ExTL and what is the relative importance of different transport pathways into the ExTL (Gettelman et al., 2011).

In this work, the ExTL is analysed based on a composite database of in-situ observations covering a large domain of latitudes in the UTLS collected during seven airborne campaigns. The objective of this study is to assess the structure of the ExTL, its vertical location and extent, as well as its meridional and seasonal variability from high resolution in-situ aircraft measurements in the Northern and Southern Hemispheres. Airborne observations offer the advantage of high vertical resolution but they are inhomogeneously distributed in time and space and a key question is whether the available observations can be representative of seasonal features in the ExTL and to which extent information on the seasonal variability can be extracted from the in-situ observational datasets. Airborne observations yield diagnostics that can be applied also to chemistry-circulation models (CCMs), to perform a process-oriented validation. Hence, dynamically based coordinate changes and diagnostics are applied to overcome the sparseness of observations and highlight the processes in the region where transition
ACPD

12, 28033-28068, 2012

\section{Extra tropical transition layer}

I. Pisso et al.

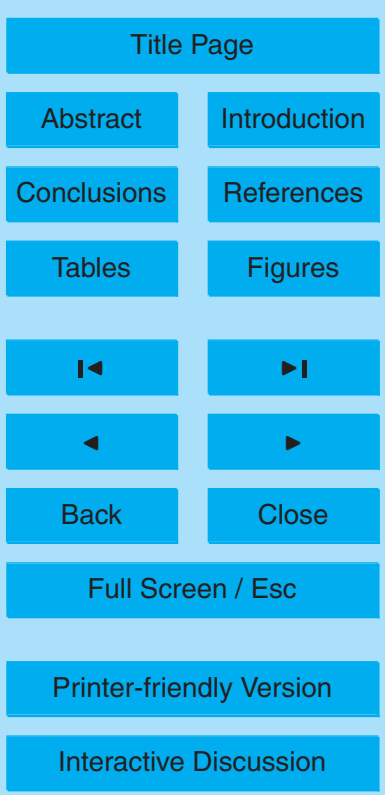


between tropospheric and stratospheric regimes occurs. The large amount of data, together with changing coordinates, provides a picture in which the transition layer can be diagnosed directly from mean tracer values take over time and surfaces of similar dynamical characteristics.

5 Section 2 describes the measurement database as well as a short description of the campaigns considered in this study and the diagnostics applied. Section 3 presents the results of the data analysis, with discussion in Sect. 4. Conclusions are given in Sect. 5.

\section{Data and methods}

10 This section describes the in-situ aircraft campaigns used in this study in Sect. 2.1 and the diagnostics derived from ECMWF winds applied to the data in Sect. 2.2. Data density will be discussed in the Sect. 3 .

\subsection{Airborne campaigns}

The in-situ observations performed during seven airborne campaigns are briefly dea function of longitude and geographical latitude Observations cover a large latitude range (from $70^{\circ} \mathrm{S}$ to $90^{\circ} \mathrm{N}$ ) and were carried out at different times of the year between February 1994 and August 2006.

- ASHOE, The Airborne Southern Hemisphere Ozone Experiment was designed to examine the causes of $\mathrm{O}_{3}$ loss in the Southern Hemisphere lower stratosphere and to investigate how the loss is related to polar, mid-latitude, and tropical processes. ASHOE was conducted in concert with the campaign Measurements for Assessing the Effects of Stratospheric Aircraft (MAESA), aimed to provide information about stratospheric photochemistry and transport for assessing the potential environmental effects of stratospheric aircraft. ASHOE/MAESA took place in

\section{ACPD}

12, 28033-28068, 2012

\section{Extra tropical transition layer}

I. Pisso et al.

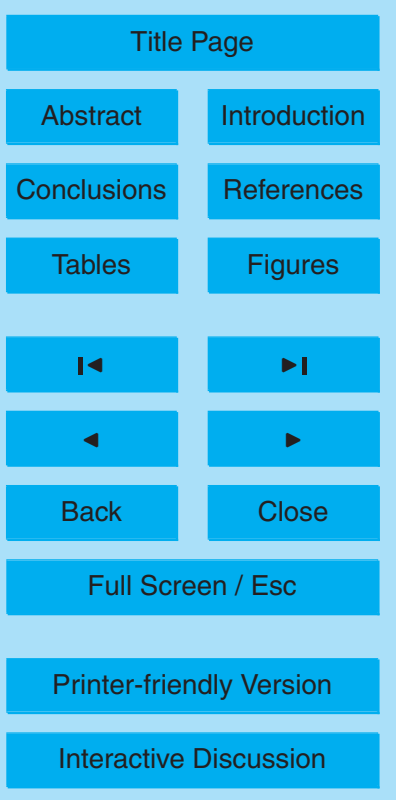


four phases through the Antarctic winter of 1994: late March to early April, late May to early June, late July to early August, and October. Observations were performed both inside and outside the Antarctic vortex primarily during 45 flights with the NASA ER-2 high altitude aircraft (Tuck et al., 1997). Details are available in Stolarski et al. (1995) and Tuck (1997).

- POLARIS the Photochemistry of $\mathrm{O}_{3}$ Loss in the Arctic Region In Summer aircraft campaign was designed to understand the seasonal behaviour of polar stratospheric $\mathrm{O}_{3}$ as it changes from very high concentrations in spring down to very low concentrations in autumn. The campaign primarily utilized the NASA ER-2 and balloon platforms based in Fairbanks, Alaska to make measurements of selected species within the reactive nitrogen $\left(\mathrm{NO}_{y}\right)$, halogen $\left(\mathrm{Cl}_{\mathrm{y}}\right)$, and odd hydrogen $\left(\mathrm{HO}_{\mathrm{x}}\right)$, as well as aerosols and other long-lived species in the lower and middle stratosphere. The POLARIS campaign included a total of $30 \mathrm{ER}-2$ flights and 3 balloon flights in 3 deployment periods in 1997: 17 April to 15 May, 24 June to 13 July, and 3 to 27 September.

- CRYSTAL-FACE (Cirrus Regional Study of Tropical Anvils and Cirrus Layers Florida Area Cirrus Experiment) was based out of Key West, Southern Florida, and included 12 flights over 27 days from 3 to 29 July 2002 (Jensen et al., 2005). All the instruments flew on NASA's WB-57F to study summertime transport in the subtropical lowermost stratosphere. In this work we make use of the in-situ measurements of $\mathrm{O}_{3}$ and $\mathrm{CO}$ obtained during July, 2002.

- The SPURT (German acronym for "trace gas transport in the tropopause region") project provided airborne high resolution in-situ measurements of a large set of trace gases including $\mathrm{O}_{3}, \mathrm{CO}$, and total water in the upper troposphere and the lowermost stratosphere above Europe in each season within the time period between November 2001 and July 2003 (Engel et al., 2006).

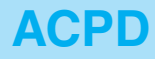

12, 28033-28068, 2012

\section{Extra tropical transition layer}

I. Pisso et al.

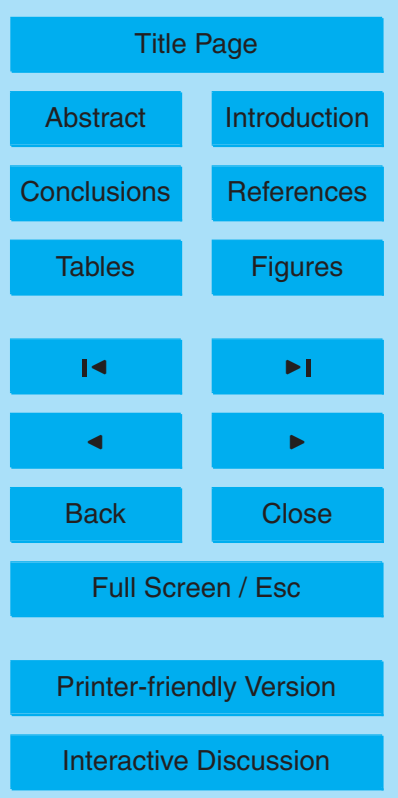


- TroCCiNOx (Tropical Convection, Cirrus, and Nitrogen Oxides Experiment) was an international project to study the tropical convection and its impact on the troposphere and lower stratosphere, transport of trace species by convection into the UTLS and impact of lightning $\mathrm{NO}_{\mathrm{x}}$. Two research aircraft, an M55 Geophysica and the DLR Falcon probed the large scale structure of the upper troposphere and lower stratosphere during the transfer flights and the measuring campaign based in Bauru, Brazil in February-March 2003-2005. The data from this campaign sampled the outflow of convective towers and hence may contain high values of tropospheric trace gases at high altitudes.
- The aim of the SCOUT-O3 (Stratospheric-Climate Links with Emphasis on the Upper Troposphere and Lower Stratosphere) campaign was to observe how water and chemical species are lifted by deep convection, and to understand how they can reach the stratosphere. The campaign was based in Darwin, Australia during November and December 2005. The M55 Geophysica and the DLR Falcon collected extensive measurements of chemical species, aerosol properties, and cloud ice particles (Brunner et al., 2009).

- AMMA - SCOUT-O3, the African Monsoon Multidisciplinary Analysis was an international project aiming to improve our knowledge and understanding of the West African monsoon (WAM) and its variability with an emphasis on daily to interannual timescales (Cairo et al., 2010; Law et al., 2010). In the frame of a large airborne research campaign, the M55 Geophysica operated from 31 July to 18 August 2006 in Ouagadougou. $\mathrm{O}_{3}$ was measured by the instrument FOZAN (Ulanovsky et al., 2001) and CO by the instrument COLD (Viciani et al., 2008).

Although the accuracy and precision of the data during the different deployments may change, the analysis of tracer gradients rather than absolute values enhances the consistency between different campaigns.

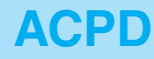

12, 28033-28068, 2012

\section{Extra tropical transition layer}

I. Pisso et al.

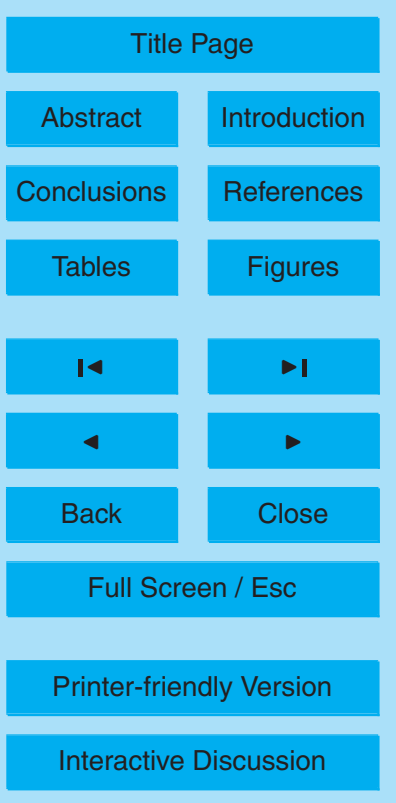




\subsection{Diagnostics based on ECMWF fields}

The conventional thermal tropopause is defined as the lowest level at which the temperature lapse rate becomes less than $2 \mathrm{~K} \mathrm{~km}^{-1}$, provided that the average lapse rate between this level and higher levels within $2 \mathrm{~km}$ does not exceed $2 \mathrm{~K} \mathrm{~km}^{-1}$ (WMO, 1957).

5 However, this definition has to be adapted in particular cases, like double tropopause occurrences and at altitudes below $500 \mathrm{hPa}$ level. Constant potential vorticity surfaces from 1.6 to $4 \mathrm{PVU}$ have been used as a proxy for the extratropical tropopause, and it has been argued that the difference between them is modest (Hoskins, 1991). From a more fundamental perspective, the tropopause is a transition layer between two different transport regimes (Haynes et al., 2001), which determines the distributions and spatial gradients of both chemical tracers like $\mathrm{O}_{3}$ (Pan et al., 2007) and "dynamical tracers" such as PV (Holton et al., 1995; Bethan et al., 1996). An alternative definition of the tropopause from a purely Lagrangian point of view has been introduced by Berthet et al. (2007), based on the calculation of the proportion $\chi_{30}$ of air masses in contact 15 with the planetary boundary layer over the last 30 days. In their Fig. 2, they show that the PV $=2$ definition deviates from $\chi$ both at high and low latitudes. It will be shown below that $\mathrm{CO}$ has a similar behavior, and the relation of this behavior with its chemical lifetime and the transport timescales and pathways in the ExTL will be analysed. The working definition for the tropopause as a control surface can influence the calculation of fluxes across such a surface Hall and Holzer (2003) and, correspondingly different definitions of the boundaries of the ExTL influence evaluation of its persistence, extent and seasonality.

Different monotonic functions of altitude can be used as a vertical coordinate for the study of the dynamics and composition of the atmosphere Kunz et al. (2011). Major meteorological centers provide routinely interpolated wind fields in vertical coordinates such as geopotential height, pressure, potential temperature $(\theta)$ and potential vorticity (PV). As for the control surface intended to calculate cross tropopause fluxes, different working definitions exist based on isopleths of quantities such as lapse rate, $\mathrm{PV}, \mathrm{O}_{3}, \theta$,

\section{ACPD}

12, 28033-28068, 2012

\section{Extra tropical transition layer}

I. Pisso et al.

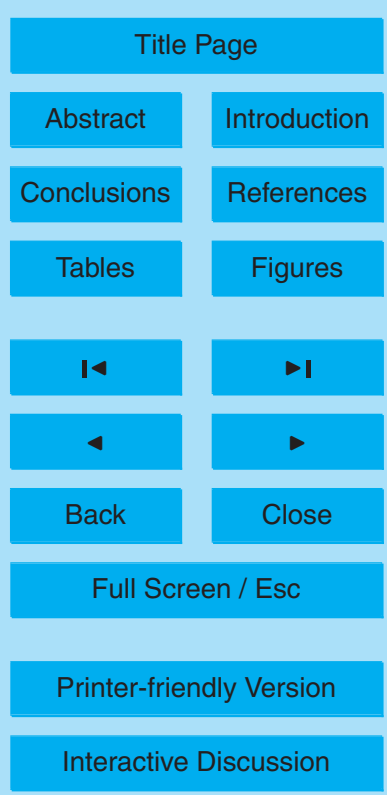


pressure. When a 3-D scalar field (such as a trace gas) is zonally averaged to obtain a two dimensional description, the information contained on zonal contours is projected onto a point, and hence the choice of the vertical and horizontal coordinates affect the interpretation of the data. The advantage of using tracer following coordinates such as 5 equivalent latitude rather than geographical coordinates, lies in preventing zonal means from losing information due to smearing out synoptic disturbances moving air masses in the meridional direction (Pan et al., 2011). Such a change to equivalent latitude coordinates is appropriate for the extra-tropics, particularly at latitudes higher than the the subtropical jets (Nash et al., 1996; Hoor et al., 2004). Conversely, in the tropics with 10 PV values approaching zero the change in horizontal coordinates has a lesser effect.

Here, for every individual observation point from the campaign data composite (typical averaging time of the order of one minute), potential temperature, potential vorticity, equivalent latitude and proxies for local tropopause height were calculated using ECMWF analyses. The analyses have a horizontal resolution of $1^{\circ} \times 1^{\circ}$ on standard 15 ECMWF theta levels (8 levels between 330 and $530 \mathrm{~K}$ ). Equivalent latitude, defined on isentropic levels, was calculated following the Nash et al. (1996) definition. The local tropopause height in $\theta$ vertical coordinate was calculated for every measurement point by interpolating the location of the 2 PVU iso-surface from ECMWF fields along a line orthogonal to the surface containing the measurement point.

$20 \quad$ Figure 2 (upper panel) shows schematically the standard representation of the structure of the UTLS (Holton et al., 1995; WMO, 2007), where the tropopause is represented by the $2 \mathrm{PVU}$ iso-surface and $380 \mathrm{~K}$ in the tropics and the ExTL is represented as a triangle above the tropopause thickening towards the poles. To characterise the transition layer in this context, it is useful to change the origin of the vertical coordi25 nate to the 2 PVU isosurface (Hoor et al., 2004; Pan et al., 2004) (Fig. 2 lower panel). The distance in $\theta(\mathrm{K})$ relative to the local $2 \mathrm{PVU}$ surface is calculated from ECMWF operational data for every individual measurement in the data composite.

Grouping subsets of measurements by equivalent latitude intervals one obtains "ensembles of profiles" suitable for statistical analysis. The chemical composition shown

\section{Extra tropical transition layer}

I. Pisso et al.

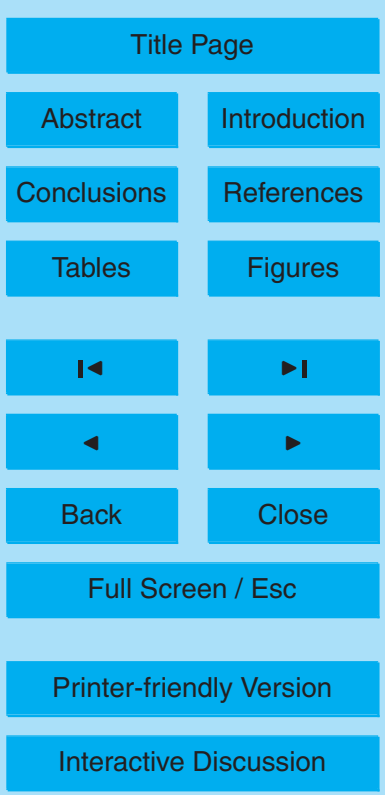


by these averaged vertical profiles is modified by changing from ground to tropopause relative vertical coordinate. Rather than a simple vertical shift one obtains an enhanced description of the the layers next to the chosen control surface acting as tropopause proxy (i.e. the $2 \mathrm{PVU}$ isosurface) in terms of chemical composition.

\section{Global tracer distributions from composite in-situ measurements: seasonal} and meridional dependence of $\mathrm{O}_{3}$ and $\mathrm{CO}$ fields

Our analysis focuses on $\mathrm{O}_{3}$ and $\mathrm{CO}$ at latitudes between $25^{\circ}$ and $65^{\circ}$ in both hemispheres, although actual lateral boundaries depend on the position of the tropical and sub-polar jets. The sources of $\mathrm{CO}$ are located within the PBL and are mainly associated with biomass combustion such as forest wildfires and anthropogenic emissions. The average lifetime of CO in the UTLS is of the order of 1-3 months and since CO concentrations are lower in the stratosphere than in the troposphere it is often used as a proxy for tropospheric air mass origin. The main source of $\mathrm{O}_{3}$ is located in the stratosphere, due to photolysis of molecular oxygen. There are sources in the tropo15 sphere, primarily secondary photochemical production from natural and anthropogenic precursors $\left(\mathrm{CH}_{4}, \mathrm{CO}\right.$, VOCs and $\left.\mathrm{NO}_{\mathrm{x}}\right)$. Nevertheless for the study of the ExTL, $\mathrm{O}_{3}$ may be, to a good approximation, considered as a stratospheric tracer.

Before presenting the results for $\mathrm{CO}$ and $\mathrm{O}_{3}$, Fig. 3 shows data density for both species from the whole data composite in absolute and relative coordinates. Data density is always higher in the Northern Hemisphere than in the Southern Hemisphere in particular for CO. Nevertheless the southern extratropical transition layer is sampled enough to allow inter-hemispheric comparisons. Kunz et al. (2008) provided a detailed analysis of airborne data comparing SPURT with MOZAIC (Measurement of OZone and water vapour by Alrbus in-service airCraft). They state that although SPURT $\mathrm{O}_{3}$
ACPD

12, 28033-28068, 2012

Extra tropical
transition layer

I. Pisso et al.

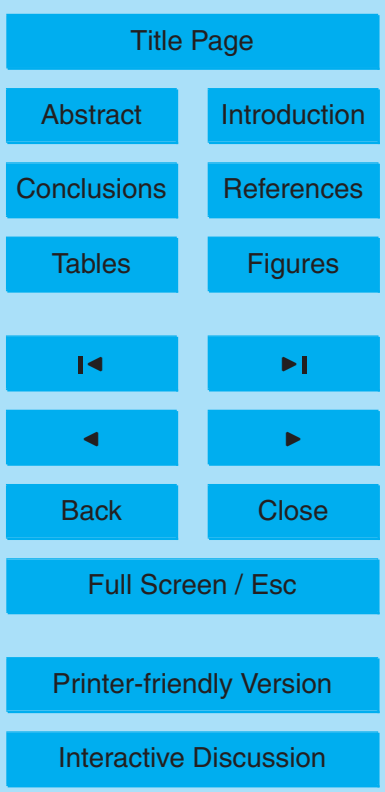
tropical UTLS it does not allow insights into intra-seasonal variability although it can 
be used for climatological investigations. In the present study we used a number of additional campaigns that enhance representativeness.

The combined use of $\Delta \theta=\theta-\theta_{2 \mathrm{PV}}$ and equivalent latitude helps to filter the seasonality associated with the vertical displacement of the tropopause, reducing the impact

5 of reversible disturbances in the zonal means. The use of equivalent latitude instead of geographical latitude helps to reduce smearing out of features due to reversible synoptic (horizontal) disturbances such as Rossby waves and to increase the meridional sampling coverage in both hemispheres.

\subsection{Analysis of December-January-February (DJF) data}

10 Figure 4 shows available $\mathrm{CO}$ and $\mathrm{O}_{3}$ data for DJF. Panels a and e show the stratosphere associated with high values of $\mathrm{O}_{3}$ (and low $\mathrm{CO}$ ) and the troposphere characterised by low $\mathrm{O}_{3}$ (and high $\mathrm{CO}$ ). In between these two regions, a there is a finite transition layer. In panel e the sharp tropical-extratropical horizontal gradients in $\mathrm{O}_{3}$ indicate the horizontal transport barrier between 350 and $400 \mathrm{~K}$. In the Northern Hemisphere the tropical-extratropical contrast is less visible in $\mathrm{CO}$ (panel a) partly due to the scarcity of data. In the Southern Hemisphere (panels a and e) the seasonal cycle in the vertical location (in $\theta$ ) of the transition layer can be observed: high values of $C O$ are observed on higher isentropes during the southern summer (in DJF) hemisphere. This is caused by increased convection in the Southern Hemisphere at this time (data in this figure includes some TROCCINOX measurements specifically targeted to measure convective towers).

Panels $b$ and $f$ show the effect of locally changing the vertical origin of $\theta$ coordinates from the ground to the position of the 2 PVU surface. It can be seen that the representation in tropopause relative coordinates makes the transition region more apparent, making it clearer to visualise the ExTL region. In particular, it helps to reduce smearing caused by averaging data affected by different tropopause heights as well as seasonal cycles, since these coordinates follow the displacement of the tropopause throughout the year (as discussed below). It can be clearly seen that in the tropopause relative

Extra tropical transition layer

I. Pisso et al.

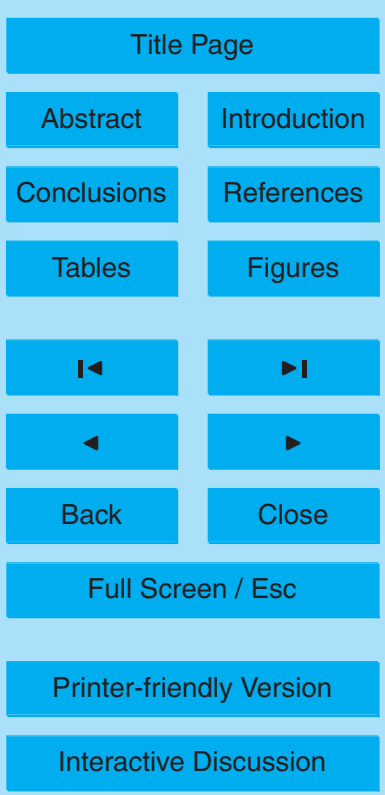


coordinates relatively high values of $\mathrm{CO}$ deviate vertically from the tropopause from the tropics towards the poles.

Seasonality of the tracer fields is strong in $\theta$-EL coordinates and is largely associated with the changes in the position of the subtropical jet, but the height of $\mathrm{CO}$ and $\mathrm{O}_{3}$

5 isopleths with respect to the 2 PVU isopleth display a weaker seasonality as seen (compare both hemispheres) in panels $b$ and $f$. As an example, high values of $\mathrm{CO}$ are found above the tropopause in the Southern Hemisphere in panel a. When the change of coordinates is applied to these data (panel b), the Northern and Southern Hemispheres display more symmetrical CO values. This illustrates to which extent the change of co10 ordinates is suitable for filtering out variability associated with change in the height of dynamical structures associated with the vertical location of the tropopause.

In order to further analyse the relationships between the distribution of chemical species and transport, vertical tracer gradients have been calculated. Zonally averaged in-situ measurement data were aggregated in equivalent latitude bands of 10 degrees.

15 The resulting data was vertically aggregated in $2 \mathrm{~K}$ intervals, extrapolated, and then smoothed with a centered running average (of 10 bins). Results for $\mathrm{CO}$ and $\mathrm{O}_{3}$ fields both in $\theta$ (panels $\mathrm{c}$ and $\mathrm{g}$ ) and in $\Delta \theta$ (panels $\mathrm{d}$ and $\mathrm{h}$ ) coordinates are shown in Fig. 4 for DJF. Panels $c$ and $d$ show that in the stratospheric overworld, far away from the surface sources, where the vertical (cross isentropic) gradients of $\mathrm{CO}$ are much lower than in the ExTL. This distribution is associated with the typical vertical profiles of CO in the UTLS displaying sharp gradients in the transition region and space average low vertical gradients in the free troposphere (well mixed and high values) and overworld (well mixed low values). In the case of $\mathrm{O}_{3}$ (panels $\mathrm{g}$ and $\mathrm{h}$ ) the distribution of gradients is different because of the different chemical processes affecting its distribution and, in 25 particular, secondary sources. Isopleths are more parallel than for $\mathrm{CO}$, following more closely the isentropes with maximum gradients at higher altitude since $\mathrm{O}_{3}$ has a major source located above, higher up in the stratosphere.

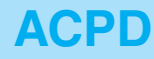

12, 28033-28068, 2012

\section{Extra tropical transition layer}

I. Pisso et al.

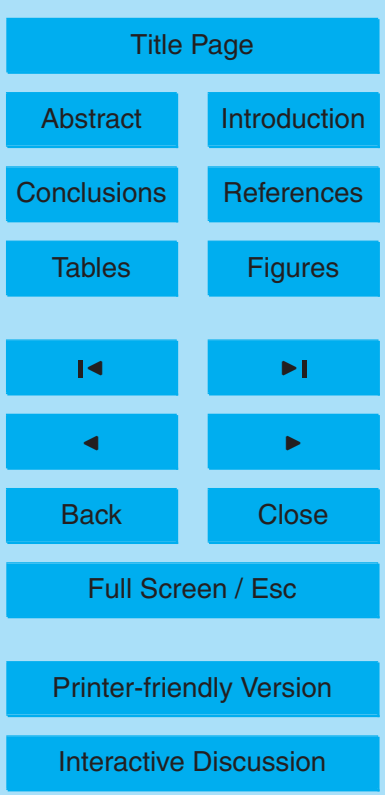




\subsection{Analysis of June-July-August (JJA) data}

In order to analyse a different season, Fig. 5 show results obtained from data collected for JJA. Panels a and e show $\mathrm{CO}$ and $\mathrm{O}_{3}$ concentrations in $\theta$ coordinates. The contrast between troposphere and stratosphere is apparent with a clear distinction between

5 tropical and extratropical regions in the Northern Hemisphere and also in the Southern Hemisphere albeit less well sampled. Panel a in Fig. 5 shows higher values of $\mathrm{CO}$ in the Northern Hemisphere above the black line (averaged tropopause) than panel a in Fig. 4 and conversely in the Southern Hemisphere. Panel e in Fig. 5 shows lower values of $\mathrm{O}_{3}$ in the Northern Hemisphere above the black line (averaged tropopause) than panel e in

10 Fig. 4 and conversely in the Southern Hemisphere. On the other hand, panels $b$ and $f$ in Figs. 5 and 4 show that changing vertical coordinates reduces seasonal differences in tracer distributions. An interesting consequence of the change of coordinates, observed in the Northern Hemisphere is the upward inclination towards the poles of $\mathrm{CO}$ isopleths respect to the $2 \mathrm{PVU}$ surface, which in this Figure corresponds to the $\mathrm{x}$-axis. This is also 15 true for $\mathrm{O}_{3}$ at lower altitudes but the isopleths appear more parallel to PV surfaces, possibly as a result of of photochemical production in the upper troposphere.

In panel $\mathrm{c}$, the vertical gradient of $\mathrm{CO}$ shows a minimum around the tropopause. In panel $g$ a maximum in the cross-isentropic gradient of $\mathrm{O}_{3}\left(\nabla_{\theta} \mathrm{O}_{3}\right)$ is consistent with the minimum of $\nabla_{\theta} \mathrm{CO}$ north of $50^{\circ} \mathrm{N}$, but in this case another maximum appears higher 20 up (around $400 \mathrm{~K}$ ) associated with the downward flux of $\mathrm{O}_{3}$ rich overworld air. In panels $\mathrm{d}$ and $\mathrm{h}$ in $\Delta \theta$ coordinates gradient isopleths of both $\mathrm{O}_{3}$ and $\mathrm{CO}$ are parallel to isopleths of tracers (panels $b$ and $f$ ). In panel $h$, the second region with higher gradients of $\mathrm{O}_{3}$ at higher altitude (around $100 \mathrm{~K}$ above the $2 \mathrm{PVU}$ surface).

In JJA there are fewer data in the Southern Hemisphere but data density is higher 25 in Northern Hemisphere summer. $\mathrm{O}_{3}$ and $\mathrm{CO}$ isopleths appear sloping respect to the $2 \mathrm{PVU}$ surface in panel $\mathrm{f}$. The same region displays a pattern of $\mathrm{O}_{3}$ consistent with $\mathrm{CO}$. This can be a signature of convective troposphere-to-stratosphere injection: panels $\mathrm{c}$ and $\mathrm{g}$ show the minimum (highest negative) gradient of $\mathrm{CO}$ and the lower $\mathrm{O}_{3}$

\section{ACPD}

12, 28033-28068, 2012

\section{Extra tropical transition layer}

I. Pisso et al.

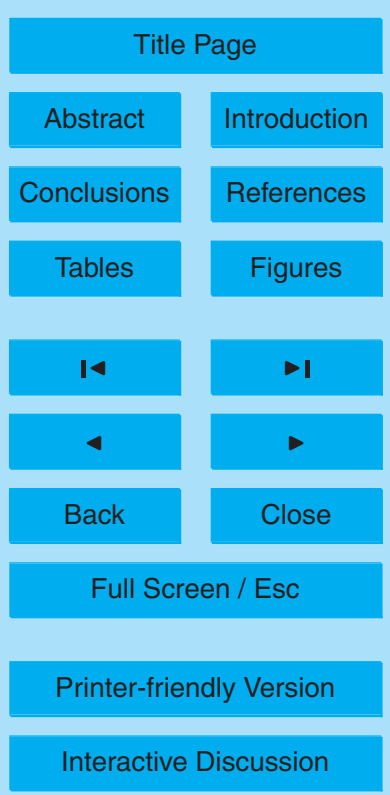


gradient maximum above the mean position of the tropopause in the Southern Hemisphere summer in Fig. 4a, c.

Panel $d$ shows the sloping isolines of $\mathrm{CO}$ gradient respect to the $2 \mathrm{PVU}$ surface. Panel h shows the lower maximum of $\mathrm{O}_{3}$ gradient coincident with the minimum in $\mathrm{CO}$ 5 towards the North Pole, but higher up towards the northern tropics due to possible enhancement of convective vertical transport in summer.

The corresponding figures for the data in MAM and SON are included as Supplement.

\subsection{Analysis of yearly average data}

10 Having shown the seasonal distributions, we can discuss general features using the whole dataset. The change into dynamical coordinates, in addition to the fact that many similarities can be identified between DJF and JJA in appropriate coordinates provides the justification for including different seasons in the same picture.

Figure 6 shows the $\mathrm{CO}$ and $\mathrm{O}_{3}$ composites as zonally averaged 2-D fields for all cam15 paigns together (more than $\sim 10^{6}$ measurement points). The spatial coverage extends from the ground to over $500 \mathrm{~K}$ and nearly from pole to pole.

This global view from in-situ measurements can be compared with the work of Strahan et al. (1999) based on ASHOE-MAESA data only, although, in that work, the zonal mean time averages were calculated in coordinates relative to the ground, and hence they are likely to smear out interesting information on structure of the UTLS in general and in particular of the ExTL.

It can be argued from the panels a and e in Fig. 6 that the iso-contours of the tracer (i.e $\mathrm{O}_{3}$ and $\mathrm{CO}$ ) follow the iso PV contours, in agreement with an adiabatic/frictionless approximation (Holton et al., 1995). On the other hand, leaving aside such an approximation and using in-situ measurements, panels $b$ and $f$ in Fig. 6 suggest that the use of absolute $\theta$ as a vertical coordinate for zonal means may mask some fine scale differences between $\mathrm{O}_{3}$ and $\mathrm{CO}$ revealed by relative $\theta$ coordinates (i.e. $\theta-\theta_{2 \mathrm{PVu}}$ ). The difference of the zonal averages in PV-relative and $\theta$ coordinates in the vertical direction

\section{Extra tropical transition layer}

I. Pisso et al.

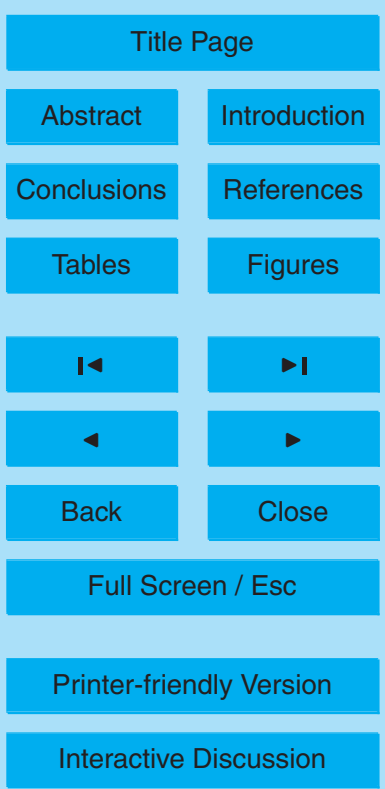


is analogous to the difference between equivalent latitude and standard latitude in the meridional direction (i.e. zonal averages are calculated following an ondulating curve). This procedure highlights the distribution of tracers relative to a chosen control surface of constant PV as shown in Fig. 6. This improvement is related to the fact that, as 5 for equivalent latitude, relative coordinates allow calculation of zonal means spanning points of similar dynamical characteristics, compared to standard geometric coordinates relative to the ground, which would be averaged in a less consistent manner.

In general, concentrations of $\mathrm{CO}$ in the Northern Hemisphere are higher than in the Southern Hemisphere owing to the unequal distribution of emissions from land masses.

10 The Northern Hemisphere appears more uniform in spite of the heterogeneous nature of the sources (continental emissions: anthropogenic pollution, forest fires). This is likely to be linked to the scarcity of the data in the Southern Hemisphere. Also, longitudinal dependence can be mentioned bearing in mind the sparseness of the observations considered. Observations collected in the vicinity of regions with large convective 15 upwelling, such as the Amazon Basin in summer in the case of TROCCINOX, show high values of $\mathrm{CO}$ in contrast to regions of lower $\mathrm{CO}$ such as the Southern Pacific in winter for data from ASHOE-MAESA.

The combined effect of longer times since last contact with the tropopause via isentropic transport and increased fraction of old stratospheric air caused by mixing leads 20 to trace gas (e.g. CO) isolines that do not follow isentropes but rather sloping surfaces, intersecting both $\theta$ and PV isopleths. Panels $b$ and $f$ in of Fig. 6 show that it is not possible to assign a constant value to the $2 \mathrm{PVU}$ surface, but the $\mathrm{CO}$ mixing ratio (and to a lesser extent also $\mathrm{O}_{3}$ ) increases with latitude. Also, transport of surface sources into the lower stratosphere may occur more easily at higher latitudes (Roiger et al., 2011).

25 For example in the Northern Hemisphere at $20^{\circ} \mathrm{N}$, the $80 \mathrm{ppbv}$ surface intersects the $2 \mathrm{PVU}$ surface, but at $80^{\circ} \mathrm{N}$ it is 20 or $30 \mathrm{~K}$ above the $2 \mathrm{PVU}$ surface. This is consistent with the trajectory study of Berthet et al. (2007) in which the 2 PVU surface includes a part of the upper troposphere. Here, this feature is found in aircraft in-situ measurements and in both hemispheres. In that sense, the intersecting surfaces express the

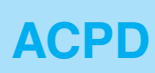

12, 28033-28068, 2012

\section{Extra tropical transition layer}

I. Pisso et al.

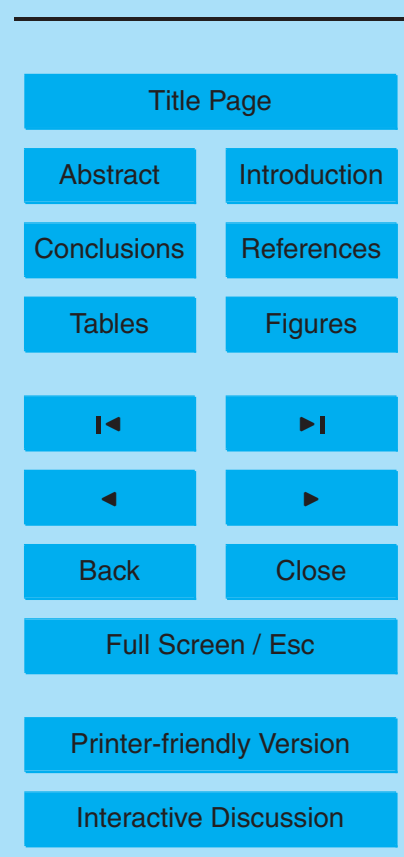


interplay between the sink of $\mathrm{CO}$ and the transport timescales and pathways in the EXTL (Hoor et al., 2004). Mixing and air mass age as a function of latitude also have an influence: irreversible transport of tropospheric air causes increased $\mathrm{CO}$ values, but the concentration decreases with time due to chemistry. Owing to the representative5 ness of the dataset used here, the "probability distribution" of an air parcel belonging to the upper or lower region can be directly inferred from the trace gas concentration. The data also suggest a preferred short scale transport path just above the subtropical jet towards the poles (Bönisch et al., 2009), e.g. Fig. 5 in the anvil-like shape of the lower $\mathrm{CO}$ values (Northern Hemisphere panel a). It is likely that the injection locations have 10 large variations following longitude and are affected by features such as the Asian monsoon, continental convection and the warm pool stratospheric gateway (Pisso et al., 2010). Also, $\mathrm{CO}$ has a tropospheric meridional gradient with higher concentrations in the Northern Hemisphere. In the case of $\mathrm{O}_{3}$, the photochemical behaviour is different from that of $\mathrm{CO} . \mathrm{O}_{3}$ production is more efficient in the UT and continues into the LS 15 (although in the $\mathrm{LS}_{3}$ lifetime is much longer and governed by dynamical processes). There are also secondary sources in the UT from lightning $\mathrm{NO}_{\mathrm{x}}$ and uplift of pollution (e.g. Singh et al., 2006). Murphy and Fahey (1994) estimated a ratio of local net production $\left(7 \times 10^{28}\right.$ molecs $\left.^{-1}\right)$ to downward stratospheric flux $\left(19 \times 10^{28}\right.$ molec $\left.^{-1}\right)$ in the LS, more than one third. Thus, tropospheric photochemical production injected into the

LS at low latitudes may compensate the downward flux of $\mathrm{O}_{3}$ rich stratospheric air at high latitudes making the meridional slope of tracer and gradient isopleths more flat.

Therefore, the combined effect of horizontal quasi isentropic transport and vertical transport from the troposphere determine isolines intersecting both $\theta$ and PV surfaces. This structure is modulated by chemical destruction in the case of $\mathrm{CO}$. In the case of

\subsection{Lagrangian comparison}

Transport in the ExTL, as described by ECMWF analyses, is consistent with the observational results presented above. Berthet et al. (2007) proposed a definition of the 
tropopause based on the isopleths of the quantity $\chi_{30 \mathrm{~d}}$, the proportion of backward trajectories having been in contact with the planetary boundary layer within a fixed period of 30 days. In order to establish a comparison with the Berthet et al. (2007) definition, we have calculated $\chi_{30 \mathrm{~d}}$ for July 2001 (same year as in Berthet et al., 2007) as 5 shown in Fig. 7 in absolute $(\theta$, left panel) and relative $(\Delta \theta$, right panel) coordinates. The aim is to compare the structure of the ExTL under the change of coordinates with respect to the local $2 \mathrm{PVU}$ surface derived from measurements with the structure of the ExTL derived from transport and a simple "ageing" chemistry. The trajectories have been calculated in backward mode with the same version of FLEXPART used in Pisso et al. (2010), where the technical details are explained. The assumed "lifetime" is of 30 days as in Berthet et al. (2007). It can be seen that $\chi_{30 \mathrm{~d}}$ follows a similar pattern to $\mathrm{CO}$. The link between $\chi_{30 \mathrm{~d}}$ and $\mathrm{CO}$ can be analysed taking into account the transport timescales and sources/sinks in the corresponding regions. Since $\mathrm{CO}$ is a photochemically decaying tracer, mixing ratios decrease on the same isentrope poleward. This is due to increasingly higher values in the age spectrum on the same isentrope moving poleward. Towards the poles, the fraction of air coming from the slower branch of the Brewer-Dobson circulation (Bönisch et al., 2009) increases, as well as the time required for faster isentropic transport driven by baroclinic eddies at the level of the jet stream. In the right panel of Fig. 7, the white lines, representing the isentropes of 320, 340 and $360 \mathrm{~K}$, display sloping angles consistent with the contours in Fig. 7 left panel. This comparison shows that transport alone is sufficient to create structures similar to those found in the measurements. The results diagnosed from the measurement composite are consistent with previous studies focusing on transport in the ExTL region (Berthet et al., 2007; Hoor et al., 2010).

\section{Discussion}

To investigate the sensitivity of the sloping tracer isopleths to the PV value chosen to define the dynamical tropopause, we have calculated the tracer distribution in new

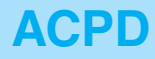

12, 28033-28068, 2012

\section{Extra tropical transition layer}

I. Pisso et al.

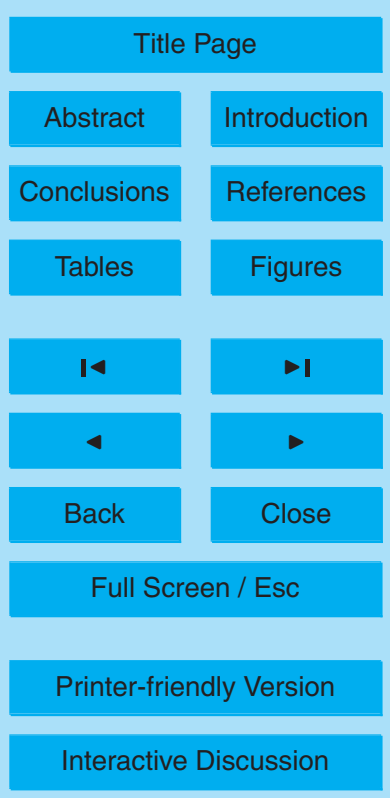


relative coordinates, changing the value of $2 \mathrm{PVU}$ to 3.5 PVU (not shown). Although there is a vertical shift due to the new origin of vertical coordinates, the general distribution of tracers remains qualitatively unchanged. A local calculation of the lapse rate tropopause for every measurement point would be interesting for comparison, but 5 it is not well suited for a large set of in-situ data since it is often ill-defined, resulting noisy patterns. Although PV is highly variable and not perfectly conserved from a large scale perspective, PV surfaces follow the seasonal variability of the extra tropical tropopause region both in height and meridional extent. Hence, they allow the integration of sparsely distributed measurements. It is worth underlining here that the 10 use of tropopause relative coordinates allows winter and summer data to be considered together. Our results suggest that for PV values in the range 1.5 to 4 , the isopleths of a tracer such as $\mathrm{CO}$ are expected to intersect PV isopleths sloping upward towards the poles. Hence, the use of the PV alone for defining the tropopause may include, at higher latitudes, stratosphere air otherwise defined as tropospheric (Berthet et al., 2007). Lower isentropes are more likely to be in contact with sources in the troposphere and so, high values of $\mathrm{CO}$ are found further away from the tropopause towards the poles than in the case of upper isentropes.

An initial working definition of ExTL based on $\mathrm{CO}$ measurements could be set with a lower limit at the $2 \mathrm{PVU}$ isosurface, and an upper limit based on a typical tropo20 spheric $C O$ value. Figures 4, 5 and 6 suggest that the surface of $80 \mathrm{ppbv}$ CO intersects the 2 PVU surface near the equivalent latitude of the subtropical jets and slopes upward toward the higher latitudes. The isentropes intersecting the 2 PVU surface can be very low at latitudes higher than $60^{\circ}$, and hence may not be suitable as a definition of the lower limit of the ExTL approaching the poles (see e.g. Fig. 6 in Kunz et al., 2011). Although $\mathrm{PV}$ and $\mathrm{O}_{3}$ have been shown to be analogous to a large extent (Haynes and Mclntyre, 1989; Holton et al., 1995), different species may exhibit different chemopauses (chemical tropopauses) depending not only on transport processes but also on chemical transformations and regions of sinks and sources. Hence, a definition based on a fixed value of $\mathrm{O}_{3}$ such as $100 \mathrm{ppbv}$ may not be consistent with a definition
ACPD

12, 28033-28068, 2012

\section{Extra tropical transition layer}

I. Pisso et al.

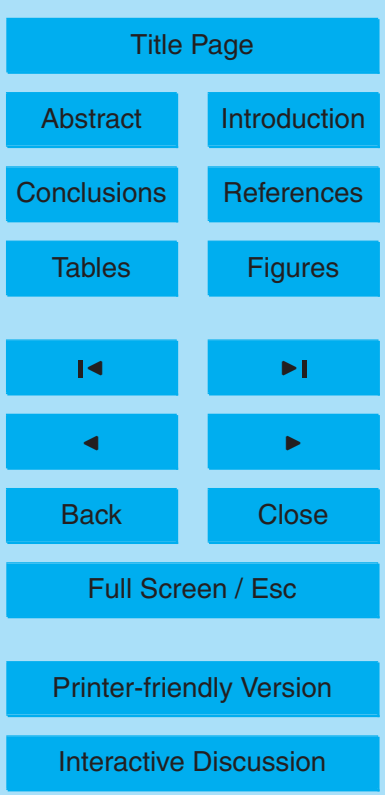


based on $\mathrm{CO}$ or $\mathrm{H}_{2} \mathrm{O}$. The concept of chemical tropopause is dependent on the characteristics of local chemical sources and sinks as well as on transport. This is illustrated in the similar behaviour found in $\mathrm{CO}$ and $\chi_{30 \mathrm{~d}}$ isopleths (Fig. 7), which is explained by the limited lifetime of the tracer $\chi_{30 \mathrm{~d}}$ analogous to the finite chemical lifetime of $\mathrm{CO}$.

5 Given that $\mathrm{CO}$ is essentially a tropospheric tracer, the maximum gradient can be used to define the upper limit of the ExTL. The analysis of the data composite provides a description of the region with highest vertical $\mathrm{CO}$ gradients sloping with respect to the PV iso-surfaces, in the same manner seen in the CO mixing ratio iso-surfaces sloping with respect to $\mathrm{PV}$ iso-surfaces. Conversely, as $\mathrm{O}_{3}$ is a stratospheric tracer, a local 10 maximum in $\mathrm{O}_{3}$ gradients could be used to mark the lower limit of the ExTL. Although the diagnosis of the vertical $\mathrm{O}_{3}$ gradient from in-situ measurements is more challenging than the analysis of $\mathrm{CO}$ gradient, our results indicate that both are consistent with local maximum (not the absolute maximum higher up in the $\mathrm{O}_{3}$ layer) in vertical $\mathrm{O}_{3}$ gradients associated with the ExTL (panels $d$ and $h$ in Fig. 6). Nevertheless, the available infor-

mation does not yield precise boundaries, and the definitions based on the regions of the highest $\mathrm{CO}$ and $\mathrm{O}_{3}$ gradients, largely overlap. The "thickness" of this region of large vertical gradients is of the order on $20 \mathrm{~K}$, in agreement with previous studies (e.g. Hoor et al. (2004) based on SPURT data). Temperature patterns also display isopleths sloping respect to $\mathrm{PV}$ iso-surfaces. This is consistent with previous studies that reported the large scale gradient of $\mathrm{CO}$ correlated with the thermal tropopause (Hegglin et al., 2009). A similar pattern can be seen in $\mathrm{H}_{2} \mathrm{O}$ using the present database, although it is more iso- $\theta$-following due to the different lifetime and thermodynamic properties (i.e. change of phase) of this tracer (not shown). Our results suggest that the transition region for a given tracer should be defined using data for that same tracer, since the transition region of one particular tracer does not necessarily match a definition based on a different tracer.

A quantitative metric for the representation of the transition layer can be defined using the sloping angle of the iso-tracer lines with respect to a given dynamically-based
ACPD

12, 28033-28068, 2012

\section{Extra tropical transition layer}

I. Pisso et al.

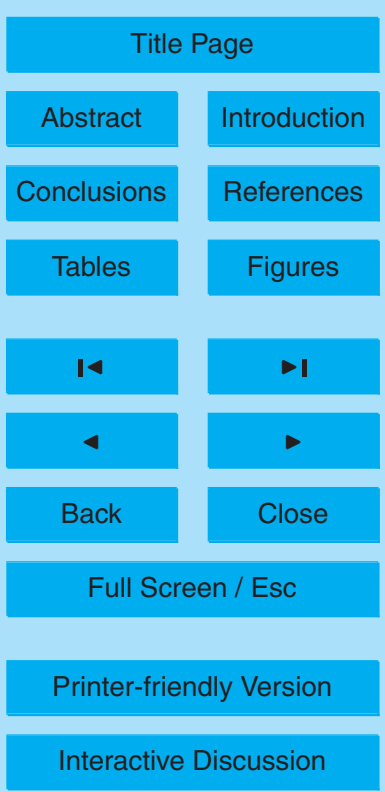


control surface such as 2 PVU for example. For example, the information about the distribution of $\mathrm{CO}$ gradients averaged in relative coordinates can be translated into standard potential temperature coordinates. The sloping geometry of the tracer and tracer gradient isopleths is related to the fact that meridional poleward transport in the 5 UTLS cannot conserve PV and $\theta$ simultaneously. The measurement composite can be used to identify the actual slope angle from in situ measurements in the UTLS region. The transverse intersection of $\mathrm{CO}$ and PV isopleths implies that the $2 \mathrm{PVU}$ (or another chosen value) surface defines air that has tropospheric signatures as well as stratospheric, this effect being more pronounced towards the polar regions. This is in 10 agreement with other trajectory-based studies such as Berthet et al. (2007). The results of our analysis are summarised in Fig. 8, which shows schematically the changing height of the top of the ExTL defined as the strongest $\mathrm{CO}$ gradient with the change of vertical coordinates. For a typical profile of $\mathrm{CO}$ in the vicinity of the ExTL, between low stratospheric values and high tropospheric values a mixed air transition layer with 15 large vertical gradients establishes. Vertical gradients vanish above and below. The tropopause is typically co-located within the strong gradient region (panel a). As disused above, in the LMS the isopleths of both $\mathrm{CO}$ and $\mathrm{CO}$ gradients intersect both $\theta$ and PV isopleths: $\alpha_{\mathrm{PV}}$ and $\alpha_{\theta}$ are the angles of the tracer isopleths with $\mathrm{PV}$ and $\theta$ isopleths respectively (panel $b$ ). Because changing the origin of the vertical coordinates is a linear transformation, the values of $\alpha_{\mathrm{PV}}$ and $\alpha_{\theta}$ are (locally) the same in $\Delta \theta$ coordinates. The advantage is that zonal averages are less smeared using data from different locations and seasons. Global climatological values can then be directly estimated from in situ measurements (panel c). Our global estimates for the average slope of the tangent of the top of the ExTL with PV and $\theta$ isopleths are $\alpha_{\theta}=1.1 \mathrm{Kdeg}^{-1} \pm 0.10 \mathrm{Kdeg}^{-1}$ and $\alpha_{\mathrm{PV}}=0.28 \mathrm{~K} \mathrm{deg}^{-1} \pm 0.11 \mathrm{~K} \mathrm{deg}^{-1}$. These estimates are based on the aircraft data described in Sect. 2.

The information obtained from the in-situ data could be combined with model analysis adopting a working definition of the ExTL that takes into account the variable distance from a chosen PV (or $\theta$ ) isosurface. This measurement-based working definition
ACPD

12, 28033-28068, 2012

\section{Extra tropical transition layer}

I. Pisso et al.

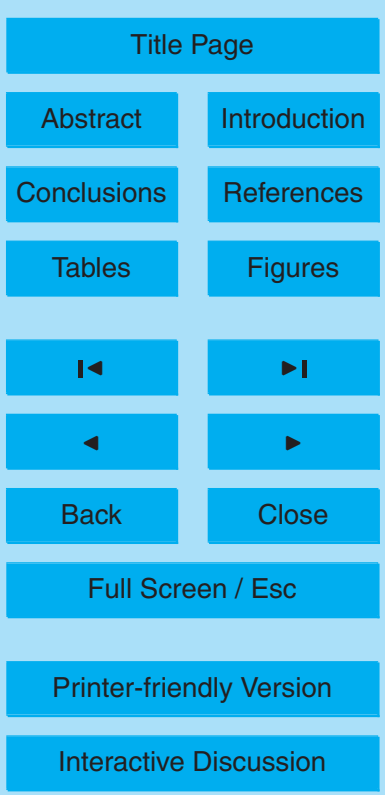


has a straightforward implementation using standard output from chemical models (e.g. as an offline or post-processing option). Although a PV iso-surface as a proxy for the tropopause is convenient for modelling studies dealing with balanced flows, because it is well defined and can be calculated directly from dynamical variables, it may introduce

5 non negligible biases. In models, the radiative forcing is computed at the tropopause because stratospheric adjustments are fast and tropospheric changes equilibrate with the surface, and hence an accurate description of the ExTL is required. Our results could also be applied to assess model representation of the time evolution of the structure of this region (Hegglin, 2010) since the change to relative coordinates reduces 10 the noise associated with temporal and zonal averages. An improved definition of the control surface can be useful for the differentiated treatment of the transition layer in Eulerian models in order to avoid double counting in the calculation of tracer fluxes.

\section{Conclusions}

In this study we have analysed the structure of the ExTL using a composite aircraft 15 measurement database. The data were collected by in-situ aircraft campaigns, providing higher temporal and spatial resolution than satellite observations. We included data from both Northern and Southern Hemispheres which allowed evaluation of the vertical distribution of tracers and tracer gradients from $70^{\circ} \mathrm{S}$ to $90^{\circ} \mathrm{N}$. In general, resolution is better in the Northern Hemisphere, where more data is available. We have used dif-

20 ferent vertical coordinates, including potential temperature relative to the dynamical tropopause. In contrast with potential temperature, the use of tropopause relative coordinates allows different seasons to be considered together. This provides a larger ensemble for climatological means.

We also calculated averaged vertical gradient fields for $\mathrm{CO}$ and $\mathrm{O}_{3}$. A maximum 25 in the vertical gradient of the $\mathrm{CO}$ field has been identified around the tropopause. The upper boundary of this region can be used as a proxy for the upper limit of the ExTL. On the other hand, although larger vertical $\mathrm{O}_{3}$ gradients appear in the overworld,

\section{Extra tropical transition layer}

I. Pisso et al.

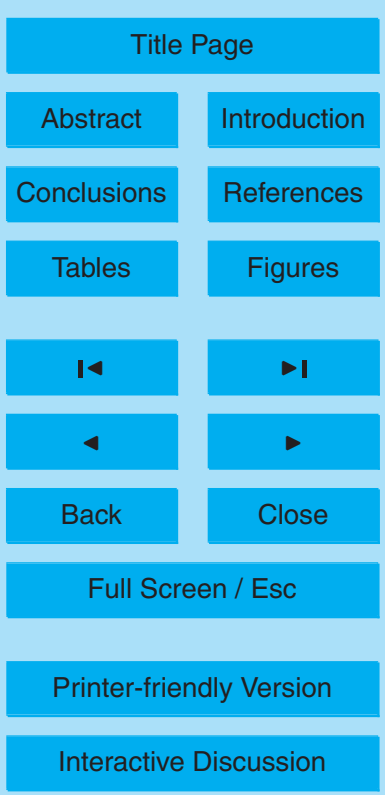


a secondary maximum is evident around the tropopause. The lower boundary of this secondary maximum can be used as a proxy for the lower boundary of the ExTL. The $\mathrm{CO}$ gradient is better defined than the $\mathrm{O}_{3}$ gradient and both are more clearly seen in the Northern Hemisphere due to larger data availability. Although both regions are cor-

5 related with the lapse rate and dynamically defined tropopause, they do not always coincide exactly. As different tracers are affected by different physico-chemical precesses, the boundaries defined with them are not necessarily identical.

We have found that the impact of isentropic and cross-isentropic transport across the 2 PVU surface increases towards the poles. The tropospheric influence (i.e. high CO 10 values) crossing the 2 PVU surface is noticeable in both the mixing ratio and the gradient fields. The general structure shown by coordinate-transformed isopleths of tracer and tracer gradients sloping respect to PV iso-surfaces is robust with respect to the $\mathrm{PV}$ value chosen for the control surface in the calculation. The relative position of the maximum vertical $\mathrm{CO}$ gradient with respect the $2 \mathrm{PVU}$ isopleth varies from $\sim 0 \mathrm{~K}$ at 20 15 to nearly $30 \mathrm{~K}$ at higher latitudes $\left(>70^{\circ}\right)$ in the Northern Hemisphere. We estimated the slope of the averaged maximum gradient surface as $0.28 \mathrm{~K} \mathrm{deg}^{-1} \pm 0.11 \mathrm{~K} \mathrm{deg}^{-1}$ (Kelvin per degree of potential latitude). The sloping $\mathrm{CO}$ isolines suggest that the $2 \mathrm{PVU}$ surface alone can be biased as a proxy for the chemical tropopause. In particular, at the high latitudes it may include tropospheric air as part of the stratosphere. Isentropic transport across constant PV surfaces is also noticeable in Lagrangian transport diagnostics such as $\chi_{30 \mathrm{~d}}$ (the proportion of air in contact with the PBL within one month Berthet et al., 2007) and are consistent with the description provided by the CO in-situ measurements.

The structure of the extratropical transition region that can deduced from in situ mea25 surements provides a benchmark for process-oriented validation of global chemical transport (CTM) or chemistry-climate models. The sloping tracer and tracer gradient isopleths with respect to $\mathrm{PV}$ isopleths can be used to define a quantitative metric for the representation of the location of the transition layer in global models. Specifically, the climatological distribution of maximum averaged tracer gradients can be assessed,

\section{Extra tropical transition layer}

I. Pisso et al.

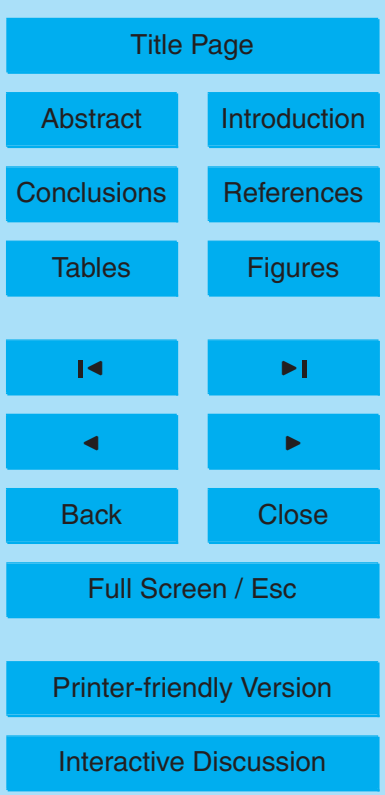


in relative potential temperature coordinates, in global models. The ability of the 3-D models to reproduce the structure of ExTL with respect to a dynamical tracer can be tested in order to evaluate the relative performance of different transport and chemical schemes and to describe the ExTL buffer zone and detect re-circulations in order to 5 avoid double counting of, for example, $\mathrm{O}_{3}$ fluxes.

The next step of the present analysis will be the direct comparison of measurement composites with CTM outputs using transformed coordinates, a use of in-situ data which is complementary to point-by-point comparisons when testing and validating global models. Alternatively, model experiments with synthetic tropospheric and 10 stratospheric tracers can be used to compare climatologies in relative coordinates of the ExTL structure with results such as those presented here. In addition, relative coordinates provide a framework for direct comparisons between Eulerian tracer experiments and Lagrangian diagnostics based on dynamical variables (e.g. $\chi_{30 \mathrm{~d}}$ ) and measurements in order to assess modelling of chemical and transport processes.

The description of the transition layer remains uncertain, especially in the Southern Hemisphere, where data availability is low. Also, even if the use of relative coordinates reduces certain biases and uncertainties in the zonal and time mean calculations, it would be useful to collect simultaneous transects with different aircraft at different longitudes in the extra-tropics in order to evaluate the performance of the coordinate changes in a given synoptic situation. Additional in-situ measurements from future campaigns and/or routine commercial route measurements such as IAGOS and CONTRAIL will help to reduce these uncertainties.

Supplementary material related to this article is available online at: http://www.atmos-chem-phys-discuss.net/12/28033/2012/ acpd-12-28033-2012-supplement.zip.

\section{Extra tropical transition layer}

I. Pisso et al.

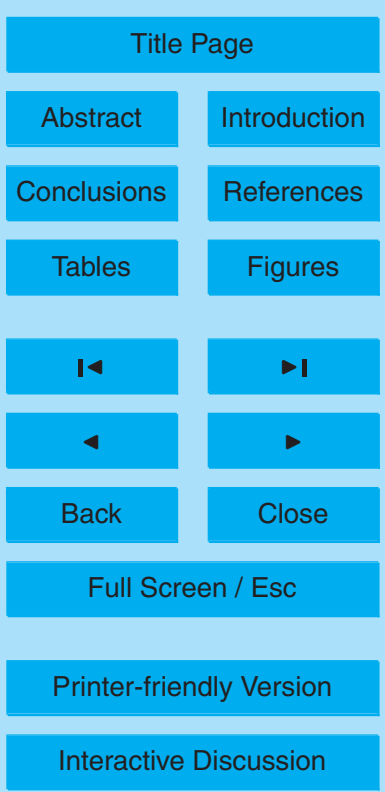


Acknowledgements. This work was supported by European Community sixth framework integrated project SCOUT-O3 (505390-GOCE-CT-2004). We acknowledge F. Jégou and J. Ajtić for early discussions. This is a sample for an acknowledgement.

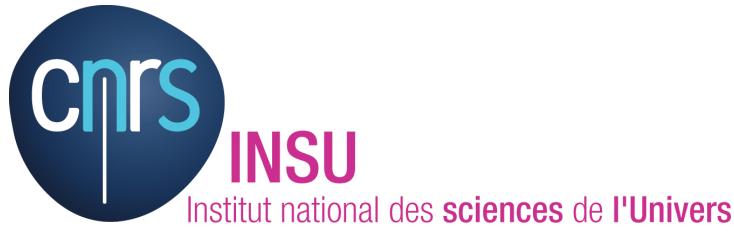

The publication of this article is financed by CNRS-INSU.

\section{References}

Berthet, G., Esler, J. G., and Haynes, P. H.: A Lagrangian perspective of the tropopause and the ventilation of the lowermost stratosphere, J. Geophys. Res., 112, D18102, doi:10.1029/2006JD008295, 2007. 28040, 28047, 28048, 28049, 28050, 28052, 28054

Bethan, S., Vaughan, G., and Reid, S. J.: A comparison of ozone and thermal tropopause heights and the impact of tropopause definition on quantifying the ozone content of the troposphere, Q. J. Roy. Meteor. Soc., 122, 929-944, doi:10.1002/qj.49712253207, 1996. 28035, 28040

Bönisch, H., Engel, A., Curtius, J., Birner, Th., and Hoor, P.: Quantifying transport into the lowermost stratosphere using simultaneous in-situ measurements of $\mathrm{SF}_{6}$ and $\mathrm{CO}_{2}$, Atmos. Chem. Phys., 9, 5905-5919, doi:10.5194/acp-9-5905-2009, 2009. 28048, 28049

Brunner, D., Siegmund, P., May, P. T., Chappel, L., Schiller, C., Müller, R., Peter, T., Fueglistaler, S., MacKenzie, A. R., Fix, A., Schlager, H., Allen, G., Fjaeraa, A. M., Streibel, M., and Harris, N. R. P.: The SCOUT-O3 Darwin Aircraft Campaign: rationale and meteorology, Atmos. Chem. Phys., 9, 93-117, doi:10.5194/acp-9-93-2009, 2009. 28039

Cairo, F., Pommereau, J. P., Law, K. S., Schlager, H., Garnier, A., Fierli, F., Ern, M., Streibel, M., Arabas, S., Borrmann, S., Berthelier, J. J., Blom, C., Christensen, T., D’Amato, F., Di Donfrancesco, G., Deshler, T., Diedhiou, A., Durry, G., Engelsen, O., Goutail, F., Harris, N. R. P., Kerstel, E. R. T., Khaykin, S., Konopka, P., Kylling, A., Larsen, N., Lebel, T., Liu, X., 28056
12, 28033-28068, 2012

\section{Extra tropical transition layer}

I. Pisso et al.

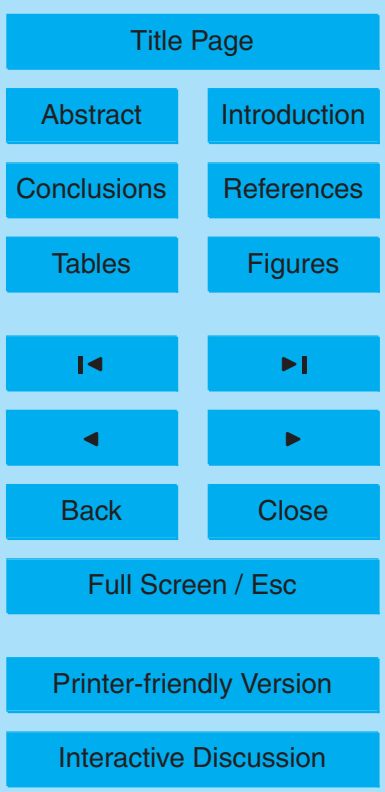


MacKenzie, A. R., Nielsen, J., Oulanowski, A., Parker, D. J., Pelon, J., Polcher, J., Pyle, J. A., Ravegnani, F., Rivière, E. D., Robinson, A. D., Röckmann, T., Schiller, C., Simões, F., Stefanutti, L., Stroh, F., Some, L., Siegmund, P., Sitnikov, N., Vernier, J. P., Volk, C. M., Voigt, C., von Hobe, M., Viciani, S., and Yushkov, V.: An introduction to the SCOUT-AMMA stratospheric aircraft, balloons and sondes campaign in West Africa, August 2006: rationale and roadmap, Atmos. Chem. Phys., 10, 2237-2256, doi:10.5194/acp-10-2237-2010, 2010. 28039

Collins, W. J., Derwent, R. G., Stevenson, D. S., Garnier, B., and Sanderson, M. G.: Effect of stratosphere-troposphere exchange on the future tropospheric ozone trend, J. Geophys.

Res., 108, 8528, doi:10.1029/2002JD002617, 2003. 28035

Engel, A., Bönisch, H., Brunner, D., Fischer, H., Franke, H., Günther, G., Gurk, C., Hegglin, M., Hoor, P., Königstedt, R., Krebsbach, M., Maser, R., Parchatka, U., Peter, T., Schell, D., Schiller, C., Schmidt, U., Spelten, N., Szabo, T., Weers, U., Wernli, H., Wetter, T., and Wirth, V.: Highly resolved observations of trace gases in the lowermost stratosphere and upper troposphere from the Spurt project: an overview, Atmos. Chem. Phys., 6, 283-301, doi:10.5194/acp-6-283-2006, 2006. 28038

Fueglistaler, S., Dessler, A. E., Dunkerton, T. J., Folkins, I., Fu, Q., and Mote, P. W.: Tropical tropopause layer, Rev. Geophys., 47, RG1004, doi:10.1029/2008RG000267, 2009. 28035

Gettelman, A., Hoor, P., Pan, L. L., Randel, W. J., Hegglin, M. I., and Birner, T.: The extratropical upper troposphere and lower stratosphere, Rev. Geophys, 49, RG3003, doi:10.1029/2011RG000355, 2011. 28036

Hall, T. M. and Holzer, M.: Advective-diffusive mass flux and implications for stratospheretroposphere exchange, Geophys. Res. Lett., 30, 1222, doi:10.1029/2002GL016419, 2003. 28040

Haynes, P. H. and Mclntyre, M. E.: On the conservation and impermeability theorems for potential vorticity, J. Atmos. Sci., 47, 2021-2031, 1989. 28050

Haynes, P. H., Scinocca, J., and Greenslade, M.: Formation and maintenance of the extratropical tropopause by baroclinic eddies, Geophys. Res. Lett., 28, 4179-4182, 2001. 28040

Hegglin, M. I.: Multimodel assessment of the upper troposphere and lower stratosphere: extratropics, J. Geophys. Res., 115, D00M09, doi:10.1029/2010JD013884, 2010. 28053

Hegglin, M. I., Boone, C. D., Manney, G. L., and Walker, K. A.: A global view of the extratropical tropopause transition layer from atmospheric chemistry experiment fourier transform spec-

\section{ACPD}

12, 28033-28068, 2012

\section{Extra tropical transition layer}

I. Pisso et al.

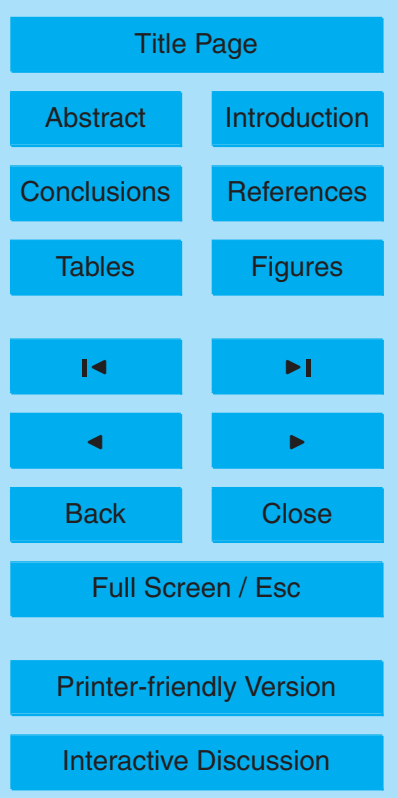


trometer $\mathrm{O}_{3}, \mathrm{H}_{2} \mathrm{O}$ and CO, J. Geophys. Res., 114, D00B11, doi:10.1029/2008JD009984, 2009. 28036, 28051

Holton, J. R., Haynes, P. H., Mclntyre, M. E., Douglass, A. R., Rood, R. B., and Pfister, L.: Stratosphere-troposphere exchange, Rev. Geophys., 33, 403-439, 1995. 28035, 28040, $528041,28046,28050$

Hoor, P., Gurk, C., Brunner, D., Hegglin, M. I., Wernli, H., and Fischer, H.: Seasonality and extent of extratropical TST derived from in-situ CO measurements during SPURT, Atmos. Chem. Phys., 4, 1427-1442, doi:10.5194/acp-4-1427-2004, 2004. 28035, 28036, 28041, 28048, 28051

10 Hoor, P., Wernli, H., Hegglin, M. I., and Bönisch, H.: Transport timescales and tracer properties in the extratropical UTLS, Atmos. Chem. Phys., 10, 7929-7944, doi:10.5194/acp-10-79292010, 2010. 28049

Hoskins, B.: Towards a PV- $\theta$ view of the general circulation, Tellus, 43, 27-35, 1991. 28040

Jensen, E., Pfister, L., Bui, T., Weinheimer, A., Weinstock, E., Smith, J., Pittman, J.,

15 Baumgardner, D., Lawson, P., and McGill, M. J.: Formation of a tropopause cirrus layer observed over Florida during CRYSTAL-FACE, J. Geophys. Res., 110, D03208, doi:10.1029/2004JD004671, 2005. 28038

Kunz, A., Schiller, C., Rohrer, F., Smit, H. G. J., Nedelec, P., and Spelten, N.: Statistical analysis of water vapour and ozone in the UT/LS observed during SPURT and MOZAIC, Atmos.

$20 \quad$ Chem. Phys., 8, 6603-6615, doi:10.5194/acp-8-6603-2008, 2008. 28042

Kunz, A., Konopka, P., Müller, R., and Pan, L. L.: Dynamical tropopause based on isentropic potential vorticity gradients, J. Geophys. Res., 116, D01110, doi:10.1029/2010JD014343, 2011. 28040, 28050

Law, K. S., Fierli, F., Cairo, F., Schlager, H., Borrmann, S., Streibel, M., Real, E., Kunkel, D., Schiller, C., Ravegnani, F., Ulanovsky, A., D'Amato, F., Viciani, S., and Volk, C. M.: Air mass origins influencing TTL chemical composition over West Africa during 2006 summer monsoon, Atmos. Chem. Phys., 10, 10753-10770, doi:10.5194/acp-10-10753-2010, 2010. 28039

Murphy, D. M. and Fahey, D. W.: An estimate of the flux of stratospheric reactive nitrogen and Ozone into the the troposphere, J. Geophys. Res., 99, 5325-5332, 1994. 28048

Nash, E. R., Newman, P. A., Rosenfield, J. E., and Schoeberl, M. R.: An objective determination of the polar vortex using Ertel's potential vorticity, J. Geophys. Res., 101, 9471-9478, 1996. 28041

\section{Extra tropical transition layer}

I. Pisso et al.

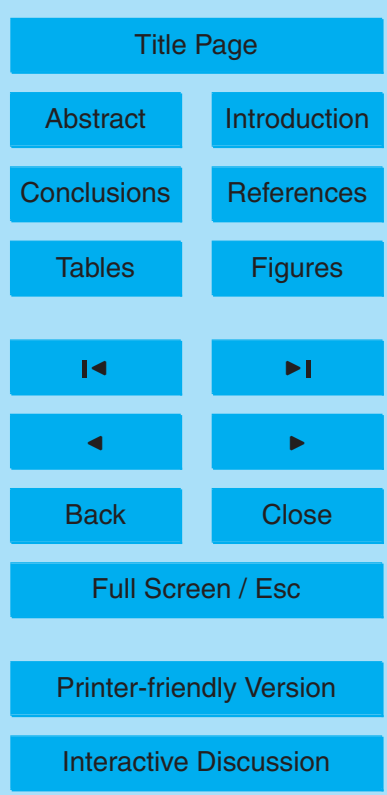


Pan, L. L., Randel, W. J., Gary, B. L., Mahoney, M. J., and Hintsa, E. J.: Definitions and sharpness of the extratropical tropopause: a trace gas perspective, J. Geophys. Res., 109, D23103, doi:10.1029/2004JD004982, 2004. 28036, 28041

Pan, L. L., Wei, J. C., Kinnison, D. E., Garcia, R. R., Wuebbles, D. J., and Brasseur, G. P.: A set 5 of diagnostics for evaluating chemistry-climate models in the extratropical tropopause region, J. Geophys. Res., 112, D09316, doi:10.1029/2006JD007792, 2007. 28040

Pisso, I., Haynes, P. H., and Law, K. S.: Emission location dependent ozone depletion potentials for very short-lived halogenated species, Atmos. Chem. Phys., 10, 12025-12036, doi:10.5194/acp-10-12025-2010, 2010. 28048, 28049

10 Singh, H. B., Brune, W. H., Crawford, J. H., Jacob, D. J., and Russell, P. B.: Overview of the summer 2004 Intercontinental Chemical Transport Experiment-North America (INTEX-A), J. Geophys. Res., 111, D24S01, doi:10.1029/2006JD007905, 2006. 28048

Stevenson, D. S., Dentener, F. J., Schultz, M. G., Ellingsen, K., van Noije, T. P. C., Wild, O., Zeng, G., Amman, M., Atherton, C. S., Bell, N., Bergmann, D. J., Bey, I., Butler, T., Cofala, J., Collins, W. J., Derwent, R. G., Doherty, R. M., Drevet, J., Eskes, H. J., Fiore, A., Gauss, M., Hauglustine, D., Horowitz, L. W., Isaksen, I. S. A., Krol, M. C., Lamarque, J.-F., Lawrence, M. G., Montanaro, V., and. G. Pitari, J. F. M., Prather, M. J., Pyle, J. A., Rast, S., Rodriguez, J. M., Sanderson, M. G., Savage, N. H., Shindell, D. T., Strahan, E. E., Sudo, K., and Szopa, S.: Multimodel ensemble simulations of present-day and near-future tropospheric ozone, J. Geophys. Res., 111, D08301, doi:10.1029/2005JD006338, 2006. 28035

Stolarski, R. S., Baughcum, S. L., Brune, W. H., Douglass, A. R., Fahey, D. W., Friedl, R. R., Liu, S. C., Plumb, R. A., Poole, L. R., Wesoky, H. L., and Worsnop, D. R.: 1995 Scientific Assessment of the Atmospheric Effects of Stratospheric Aircraft, NASA Reference Publication 1381, National Aeronautics and Space Administration, 106 pp., November 1995. 28038

Strahan, S., Lowenstein, M., and Podolske, J.: Climatology and Small-scale structure of lower stratospheric $\mathrm{N}_{2} \mathrm{O}$ based on in situ observations, J. Geophys. Res., 104, 2195-2208, doi:10.1029/1998JD200075, 1999. 28046

Tuck, A. F.: Introduction to special section: ASHOE/MAESA, J. Geophys. Res., 102, 3899-3899, doi:10.1029/96JD03920, 1997. 28038

so Tuck, A. F., Baumgardner, D., Chan, K. R., Dye, J. E., Elkins, J. W., Hovde, S. J., Kelly, K. K., Loewenstein, M., Margitan, J. J., May, R. D., Podolske, J. R., Proffitt, M. H., Rosenlof, K. H., Smith, W. L., Webster, C. R., and Wilson, J. C.: The Brewer-Dobson circulation in the 
light of high altitude in situ aircraft observations, Q. J. Roy. Meteor. Soc., 123, 1-69, doi:10.1002/qj.49712353702, 1997. 28038

Ulanovsky, A., Yushkov, V., Sitnikov, N., and Ravegnani, F.: The FOZAN-II fastresponse chemiluminescent airborne ozone analyzer, Instrum. Exp. Tech., 44, 249-256, doi:10.1023/A:1017535608026, 2001. 28039

Viciani, S., D’Amato, F., Mazzinghi, P., Castagnoli, F., Toci, G., and Werle, P.: A cryogenically operated laser diode spectrometer for airborne measurement of stratospheric trace gases, Appl. Phys. B-Lasers O., 90, 581-592, doi:10.1007/s00340-007-2885-2, 2008. 28039

WMO: Scientific Assessment of Ozone Depletion: 2006, Tech. Rep. 50, World Meteorological

Organization, Geneva, 2007. 28034, 28041

\section{ACPD}

12, 28033-28068, 2012

\section{Extra tropical \\ transition layer}

I. Pisso et al.

Title Page

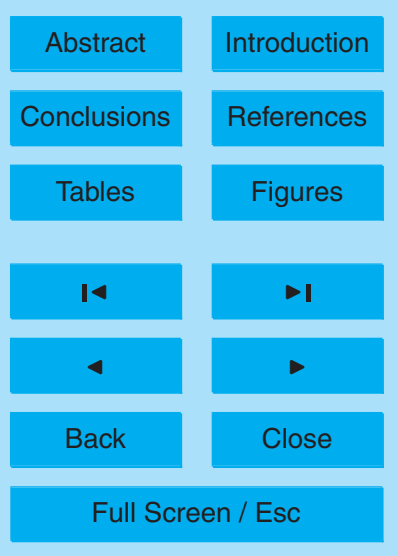

Printer-friendly Version

Interactive Discussion 


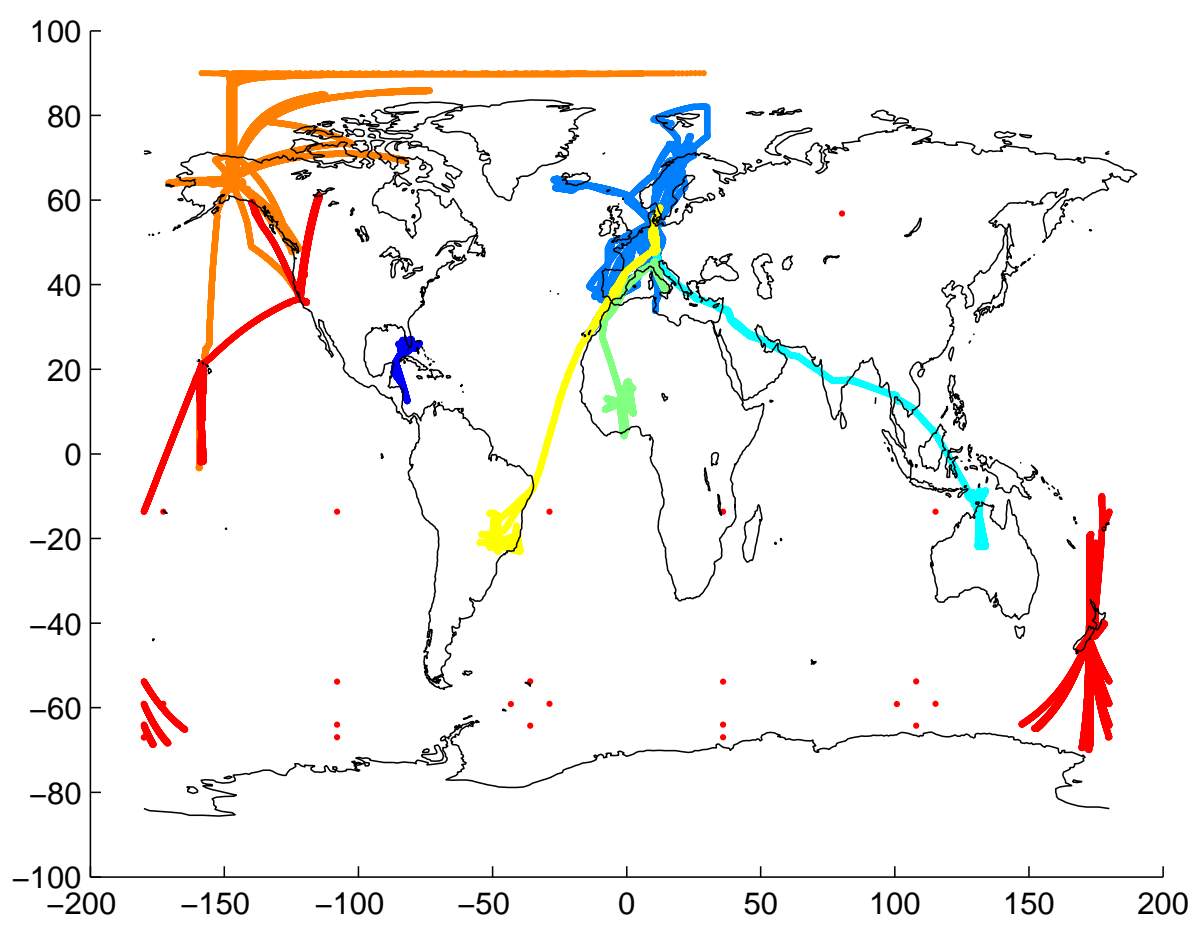

\section{ACPD}

12, 28033-28068, 2012

\section{Extra tropical transition layer}

I. Pisso et al.

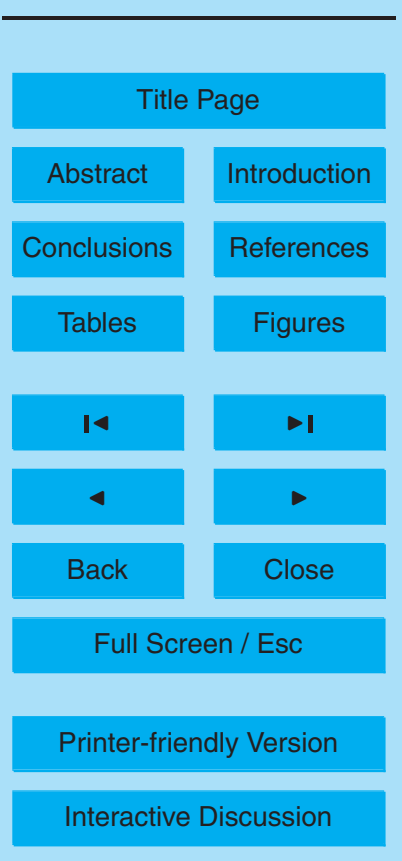

Fig. 1. Location of the campaigns used in this study: ASHOE-MAESA (red), POLARIS (orange), CRYSTAL-FACE (dark blue), SPURT (light blue), TroCCiNOx (yellow), SCOUT-O3 (cyan), AMMA (green). Individual dots represent individual observations. 


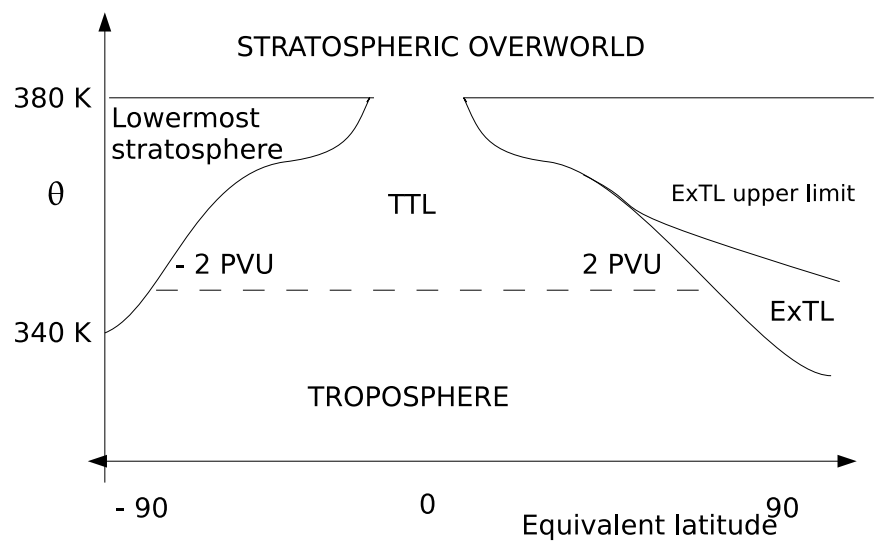

\section{ACPD}

12, 28033-28068, 2012

\section{Extra tropical transition layer}

I. Pisso et al.
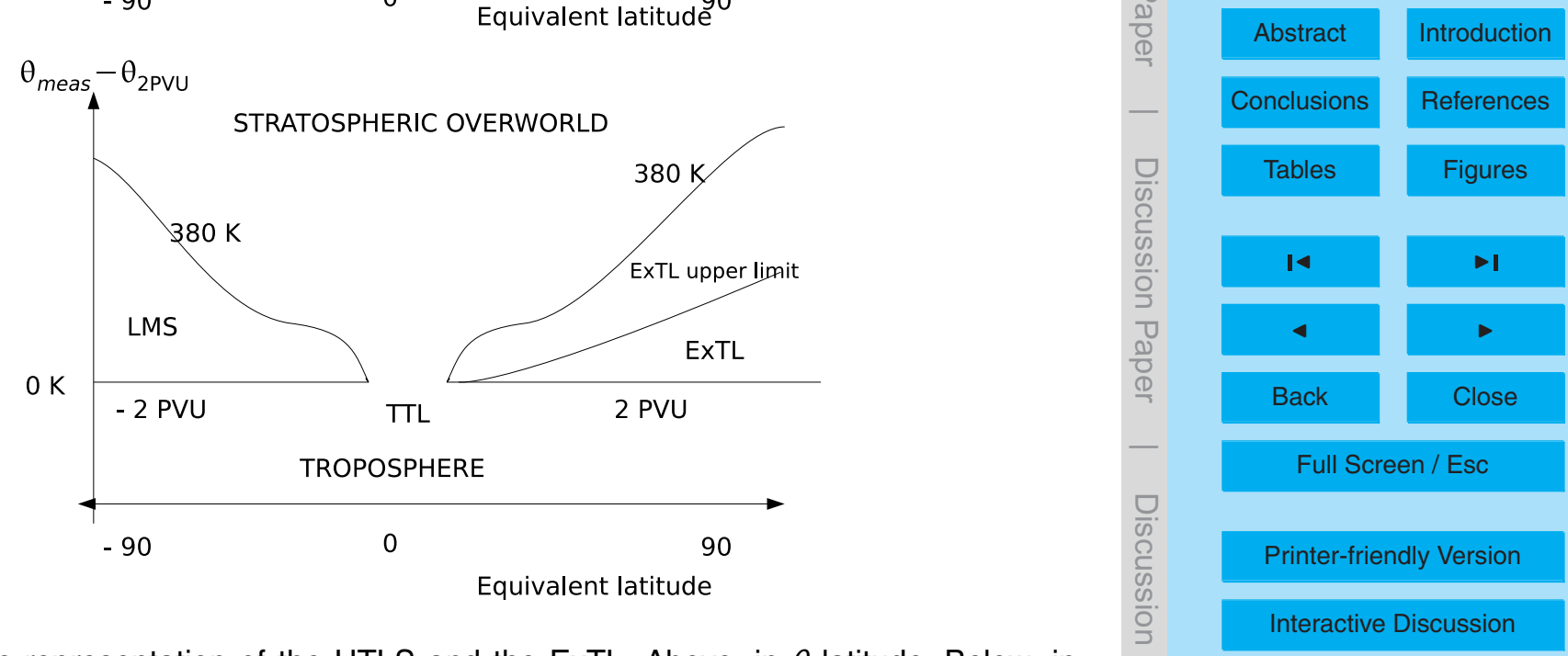

Fig. 2. Schematic representation of the UTLS and the ExTL. Above: in $\theta$-latitude. Below: in $\Delta \theta$-latitude. 

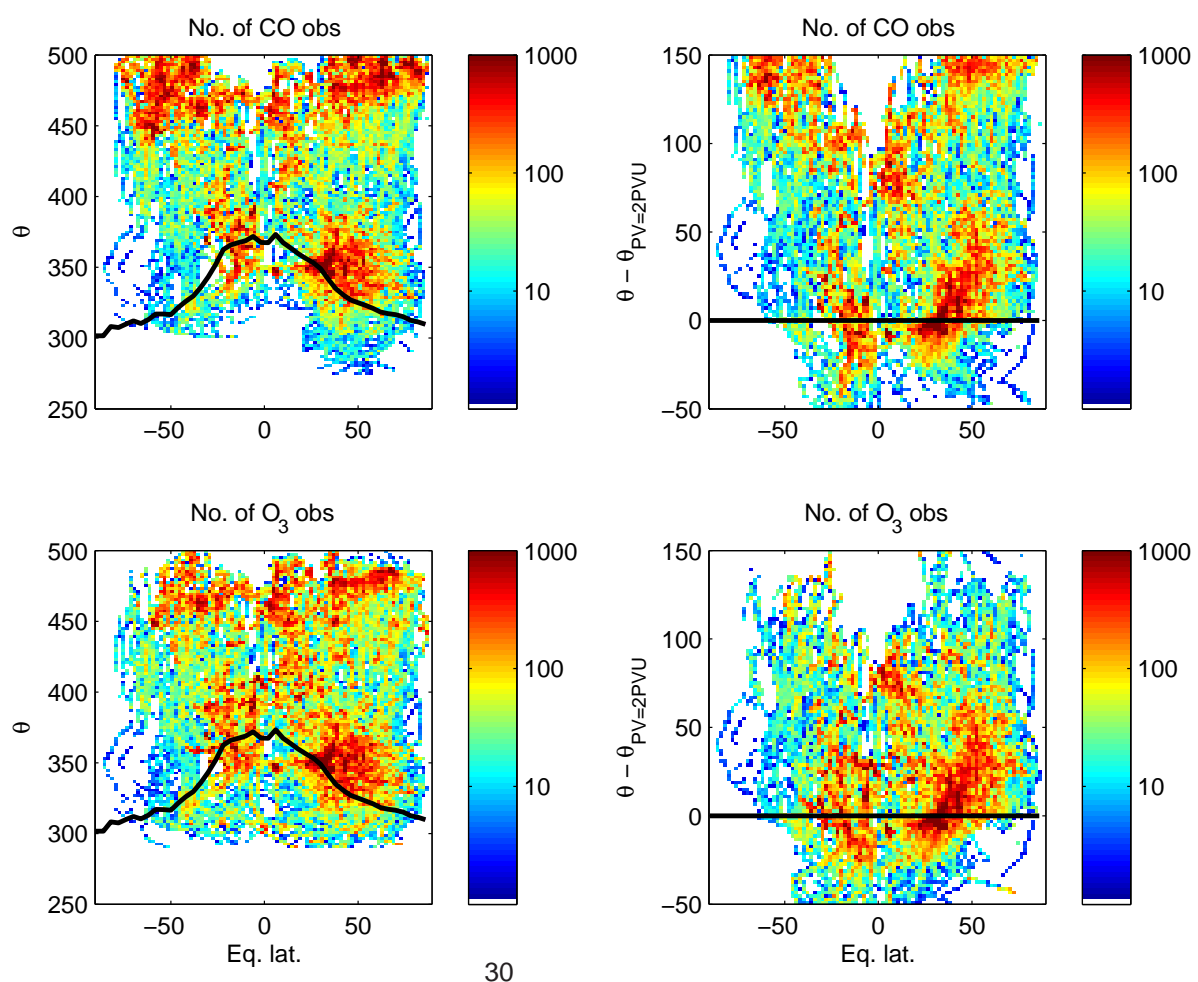

Fig. 3. Data density (Number of observations per bin of $2 \mathrm{~K} \times 2^{\circ}$ ) for all data in the composite. Upper row: $\mathrm{CO}$ in ppbv. Lower row: $\mathrm{O}_{3}$ in ppbv. The Left column shows the distribution in $\theta$ coordinates; the black line represents the averaged tropopause from ECMWF. Right column shows the distribution in $\Delta \theta$ coordinates; the black line represents the $2 \mathrm{PVU}$ isopleth.

\section{ACPD}

12, 28033-28068, 2012

\section{Extra tropical transition layer}

I. Pisso et al.
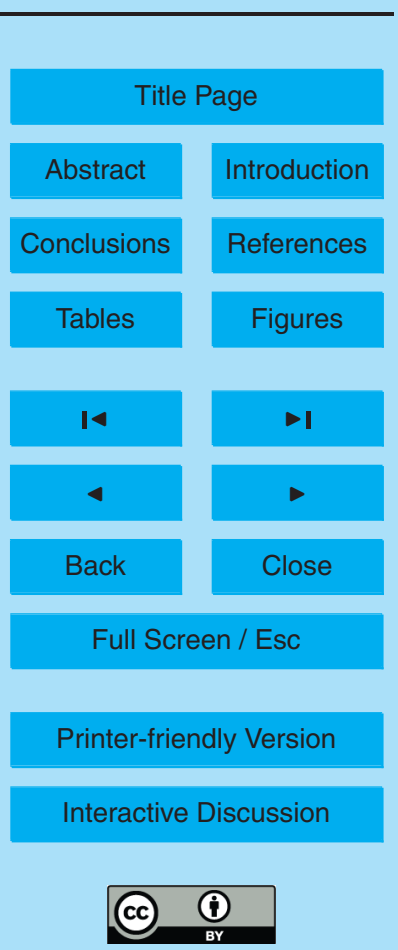

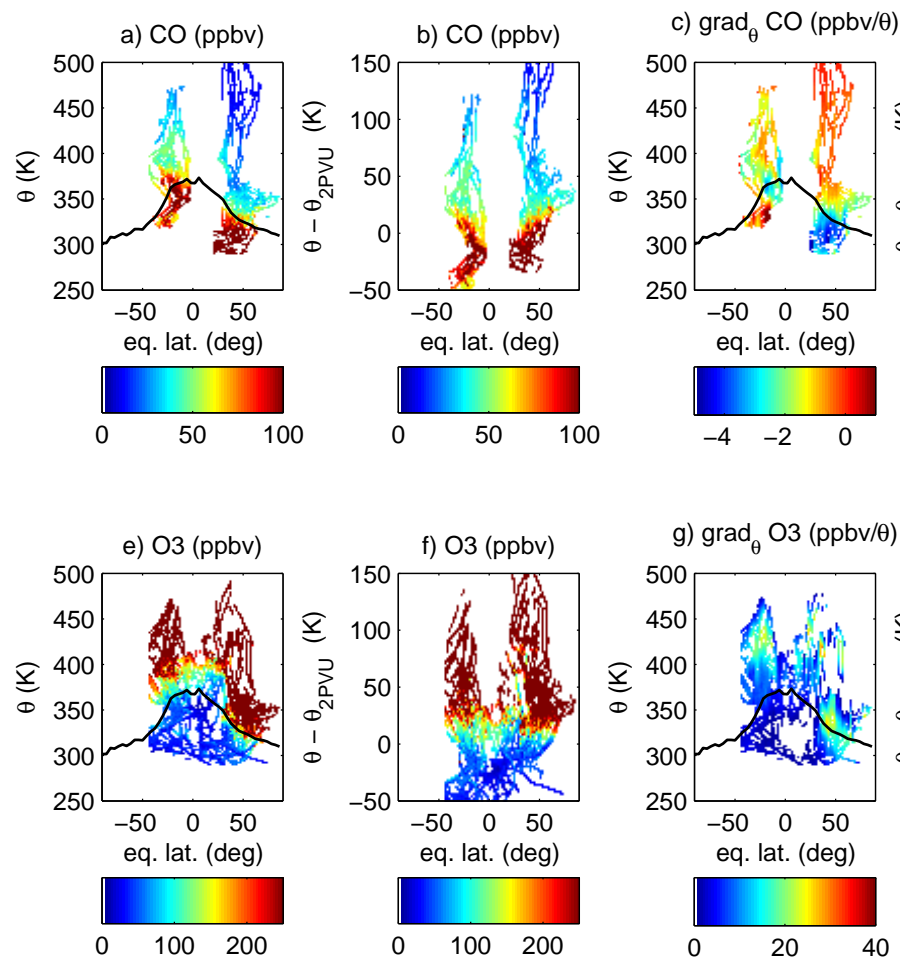

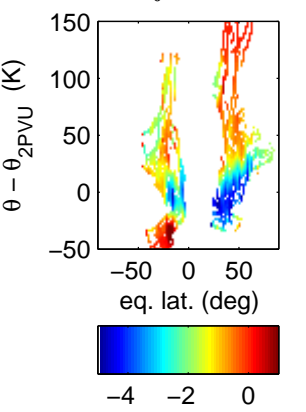

h) $\operatorname{grad}_{\theta} \mathrm{O} 3(\mathrm{ppbv} / \theta)$
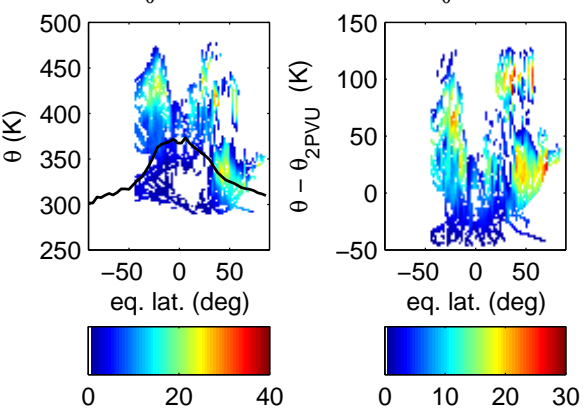

d) $\operatorname{grad}_{\theta} \mathrm{CO}(\mathrm{ppbv} / \theta)$

\section{ACPD}

12, 28033-28068, 2012

\section{Extra tropical transition layer}

I. Pisso et al.

Fig. 4. Diagnostics for data selected from December-January-February. (a) $\mathrm{CO}$ in theta vertical coordinates. (b) $\mathrm{CO}$ in theta coordinates with respect to the local position of the $2 \mathrm{PVU}$ surface. (c) Vertical gradient of $\mathrm{CO}$. (d) Vertical gradient of $\mathrm{CO}$ in theta coordinates respect to the local position of the $2 \mathrm{PVU}$ surface. (e) $\mathrm{O}_{3}$ in theta vertical coordinates. (f) $\mathrm{O}_{3}$ in theta coordinates respect to the local position of the $2 \mathrm{PVU}$ surface. (g) Vertical gradient of $\mathrm{O}_{3}$. (h) Vertical gradient of $\mathrm{O}_{3}$ in theta coordinates respect to the local position of the $2 \mathrm{PVU}$ surface. 


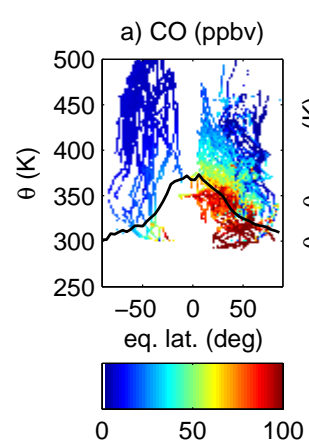

b) $\mathrm{CO}$ (ppbv)
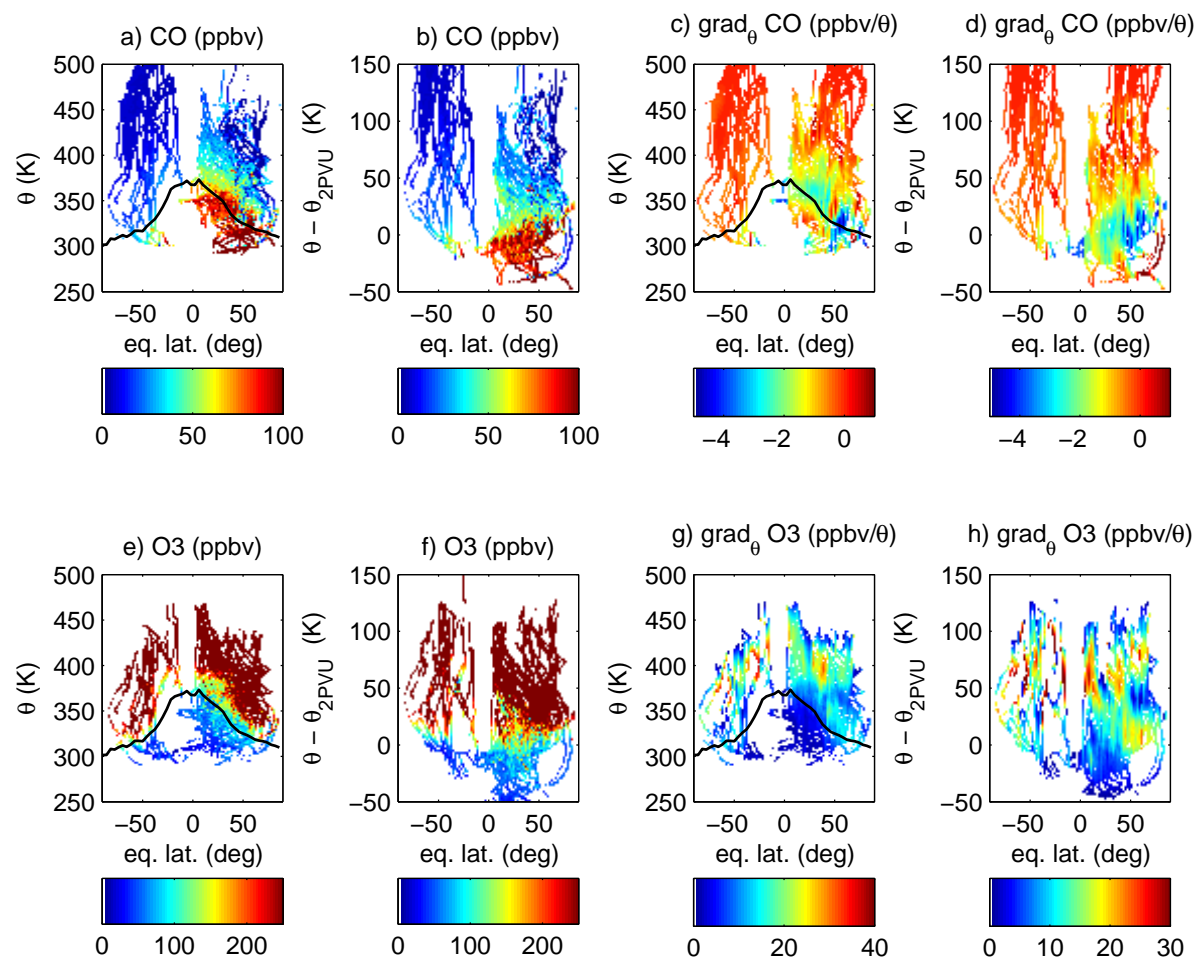

h) $\operatorname{grad}_{\theta} \mathrm{O} 3(\mathrm{ppbv} / \theta)$

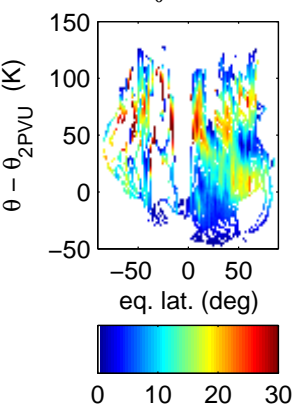

\section{ACPD}

12, 28033-28068, 2012

\section{Extra tropical transition layer}

I. Pisso et al.

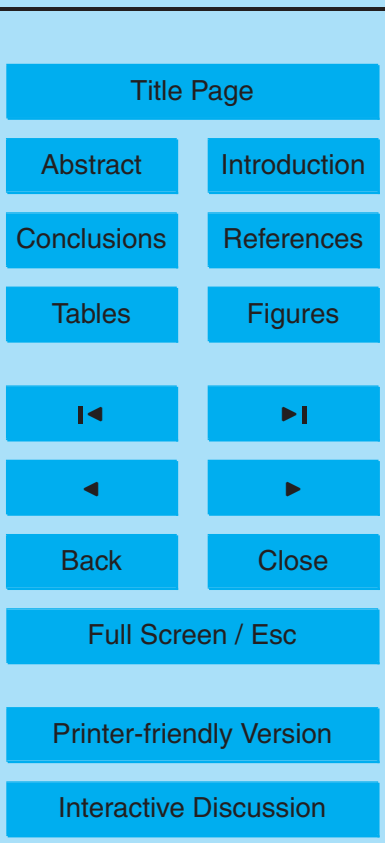

Fig. 5. Diagnostics for data selected from June-July-August. (a) $\mathrm{CO}$ in theta vertical coordinates. (b) $\mathrm{CO}$ in theta coordinates with respect to the local position of the $2 \mathrm{PVU}$ surface. (c) Vertical gradient of $\mathrm{CO}$. (d) Vertical gradient of $\mathrm{CO}$ in theta coordinates respect to the local position of the $2 \mathrm{PVU}$ surface. (e) $\mathrm{O}_{3}$ in theta vertical coordinates. (f) $\mathrm{O}_{3}$ in theta coordinates respect to the local position of the $2 \mathrm{PVU}$ surface. (g) Vertical gradient of $\mathrm{O}_{3}$. (h) Vertical gradient of $\mathrm{O}_{3}$ in theta coordinates respect to the local position of the $2 \mathrm{PVU}$ surface. 

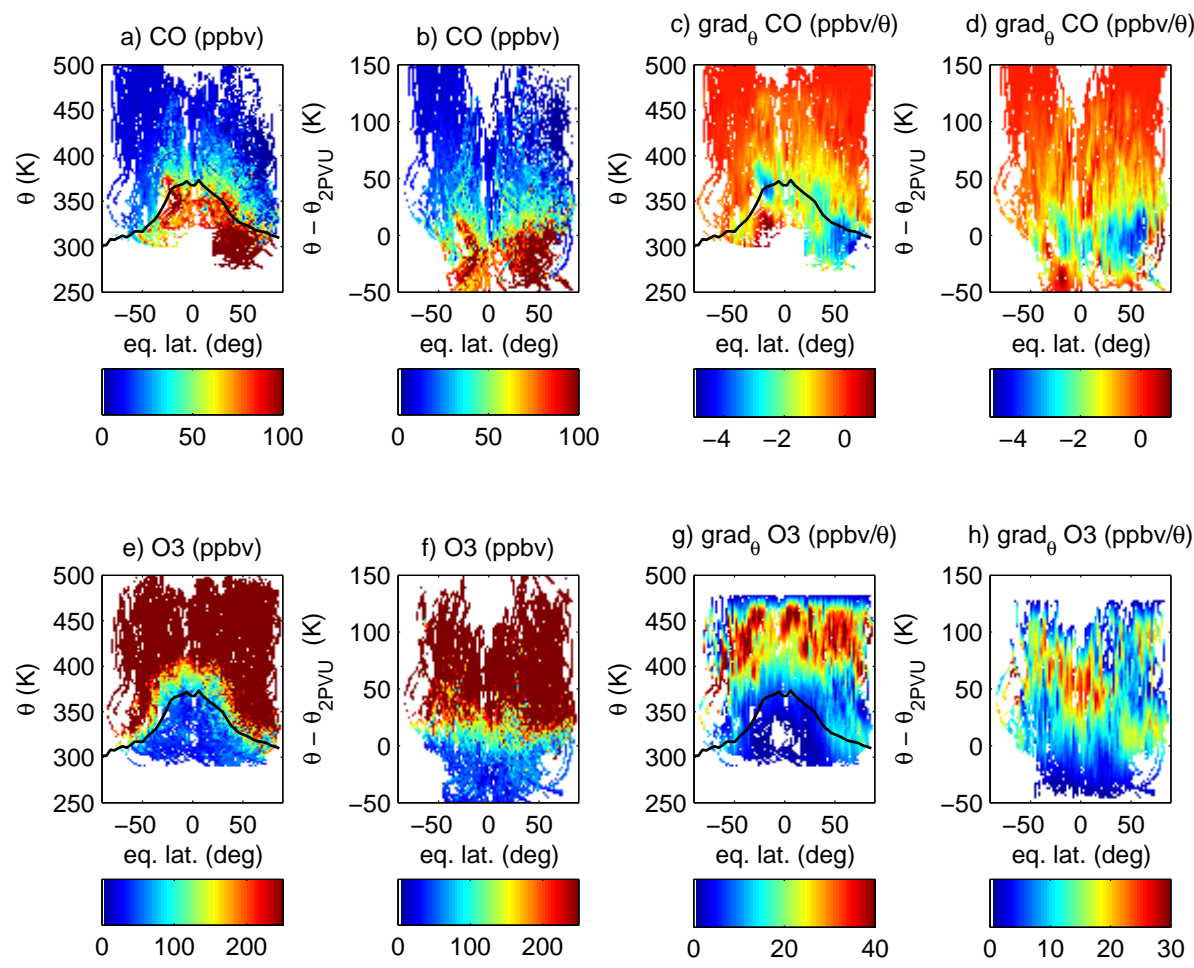

h) $\operatorname{grad}_{\theta} \mathrm{O} 3(\mathrm{ppbv} / \theta)$

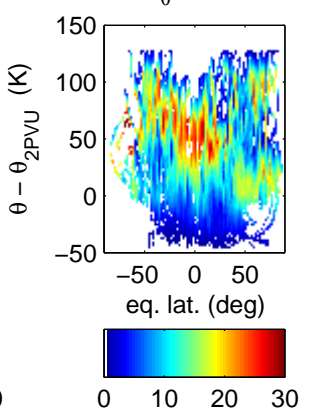

Fig. 6. Diagnostics for all available data. (a) $\mathrm{CO}$ in theta vertical coordinates. (b) $\mathrm{CO}$ in theta coordinates with respect to the local position of the $2 \mathrm{PVU}$ surface. (c) Vertical gradient of CO. (d) Vertical gradient of $\mathrm{CO}$ in theta coordinates respect to the local position of the $2 \mathrm{PVU}$ surface. (e) $\mathrm{O}_{3}$ in theta vertical coordinates. (f) $\mathrm{O}_{3}$ in theta coordinates respect to the local position of the $2 \mathrm{PVU}$ surface. (g) Vertical gradient of $\mathrm{O}_{3}$. (h) Vertical gradient of $\mathrm{O}_{3}$ in theta coordinates respect to the local position of the $2 \mathrm{PVU}$ surface.

\section{ACPD}

12, 28033-28068, 2012

\section{Extra tropical transition layer}

I. Pisso et al.

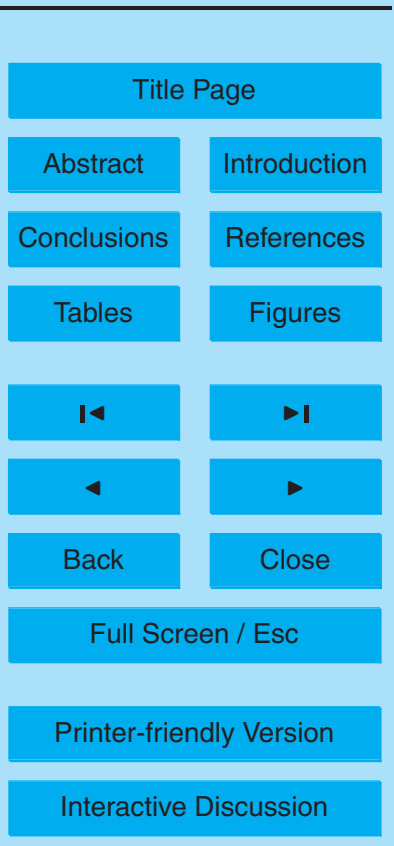



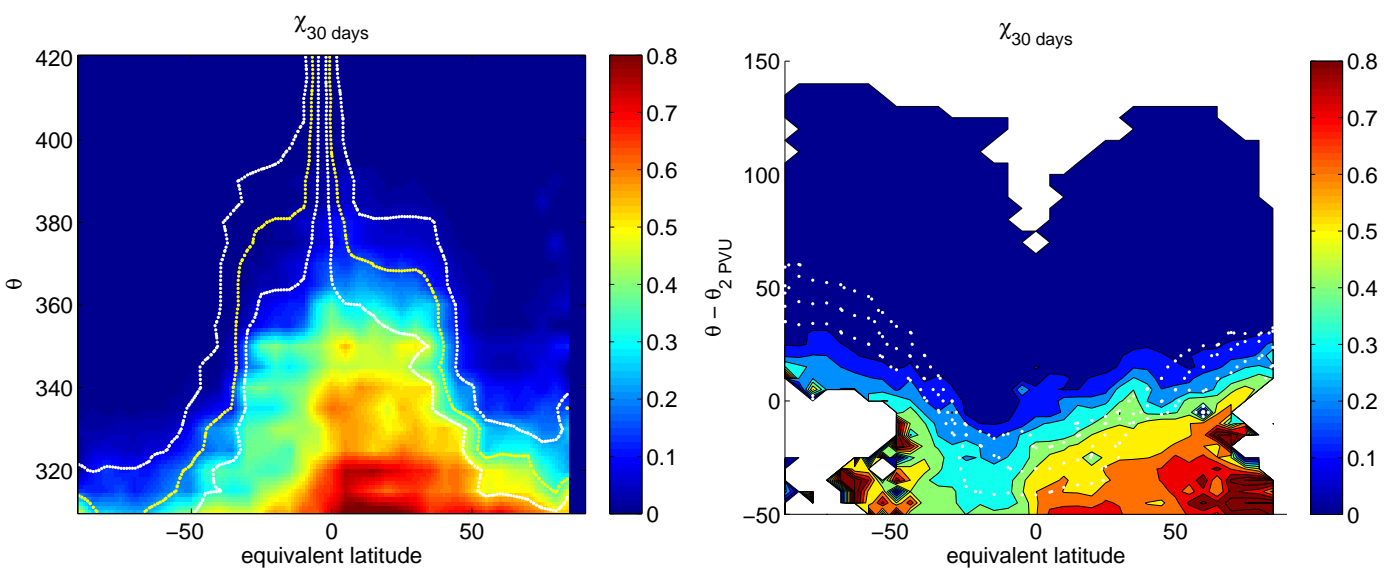

Fig. 7. Left panel: $\chi_{30 \text { day }}$ from Lagrangian trajectories in $\theta(K)$ for 1 July 2001 Right panel: $\chi_{30 \text { day }}$ from Lagrangian trajectories in $\theta-\theta_{2 \mathrm{PVU}}(\mathrm{K})$ for 1 July 2001. White dotted lines correspond to the surfaces of 2, 4 and $6 \mathrm{PVU}$ in absolute value.

\section{ACPD}

12, 28033-28068, 2012

\section{Extra tropical transition layer}

I. Pisso et al.

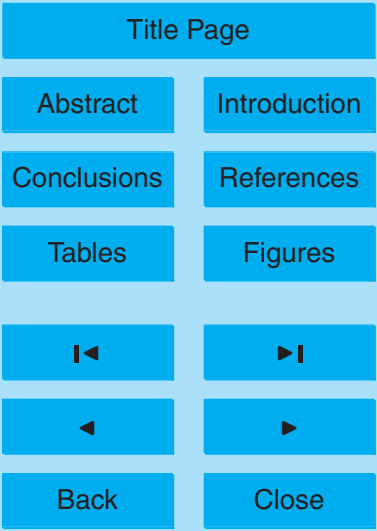

Full Screen / Esc

Printer-friendly Version

Interactive Discussion 


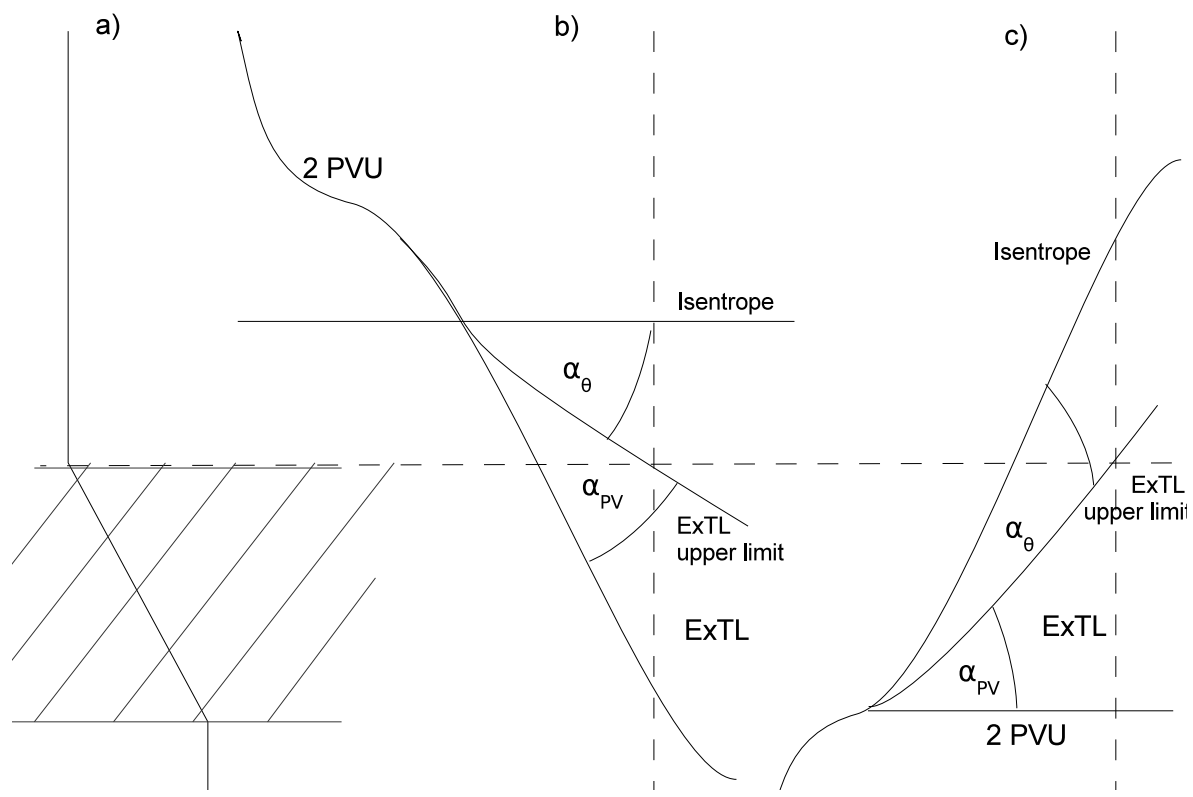

Fig. 8. (a) Schematic of a typical profile of $C O$ in the vicinity of the ExTL. The abscissa represents $\mathrm{CO}$ mixing ratio whereas the ordinate represents the vertical coordinate in potential temperature. Between low stratospheric values and high tropospheric values a mixed air transition layer with large vertical gradients establishes. Vertical gradients vanish above and below the mixed region. The tropopause is typically located within the shaded region. (b) Schematic representation of the LMS in $\theta$ coordinates, with the ExTL upper limit intersecting both $\theta$ and PV isopleths: $\alpha_{\mathrm{PV}}$ and $\alpha_{\theta}$ are the angles of the tracer isopleths with PV and $\theta$ isopleths respectively. The vertical dashed line indicates the location of the vertical profile (a) within the 2-D schematic (b). The horizontal dashed line connects the representation of the top of the ExTL in (b) with the point of vanishing vertical gradients in (a). (c) Relative vertical coordinates yield estimates of the values of $\alpha_{\mathrm{PV}}$ and $\alpha_{\theta}$ directly from in situ measurements.

\section{ACPD}

12, 28033-28068, 2012

\section{Extra tropical transition layer}

I. Pisso et al.

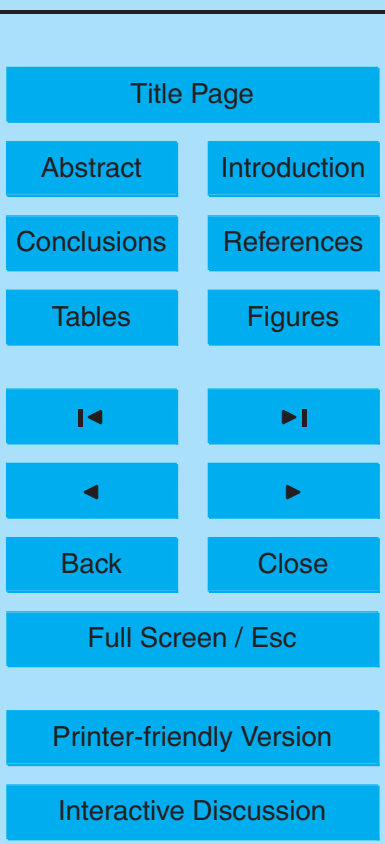

